\title{
Compositional effects on the ignition of FACE gasolines
}

S. Mani Sarathy ${ }^{1 *}$, Goutham Kukkadapu ${ }^{2}$, Marco Mehl $^{3}$, Tamour Javed ${ }^{1}$, Ahfaz Ahmed ${ }^{1}$, Nimal Naser ${ }^{1}$, Aniket Tekawade ${ }^{4}$, Graham Kosiba ${ }^{4}$, Mohammed AlAbbad ${ }^{1}$, Eshan Singh ${ }^{1}$, Sungwoo Park ${ }^{1}$, Mariam Al Rashidi ${ }^{1}$, Suk Ho Chung ${ }^{1}$, William L. Roberts ${ }^{1}$, Matthew A. Oehlschlaeger ${ }^{4}$, Chih-Jen Sung ${ }^{2}$, Aamir Farooq $^{1}$

${ }^{1}$ Clean Combustion Research Center, King Abdullah University of Science and Technology, Kingdom of Saudi Arabia

${ }^{2}$ Department of Mechanical Engineering, University of Connecticut, Storrs, CT, United States

${ }^{3}$ Lawrence Livermore National Laboratory, Livermore, CA, USA

${ }^{4}$ Mechanical, Aerospace, and Nuclear Engineering, Rensselaer Polytechnic Institute, Troy, NY, USA

* Corresponding author: mani.sarathy@ kaust.edu.sa

\begin{abstract}
As regulatory measures for improved fuel economy and decreased emissions are pushing gasoline engine combustion technologies towards extreme conditions (i.e., boosted and intercooled intake with exhaust gas recirculation), fuel ignition characteristics become increasingly important for enabling stable operation. This study explores the effects of chemical composition on the fundamental ignition behavior of gasoline fuels. Two well-characterized, high-octane, non-oxygenated FACE (Fuels for Advanced Combustion Engines) gasolines, FACE F and FACE G, having similar antiknock indices but different octane sensitivities and chemical compositions are studied. Ignition experiments were conducted in shock tubes and a rapid compression machine (RCM) at nominal pressures of 20 and 40 atm, equivalence ratios of 0.5 and 1.0, and temperatures ranging from 650 to $1270 \mathrm{~K}$. Results at temperatures above $900 \mathrm{~K}$ indicate that ignition delay time is similar for these fuels. However, RCM measurements below $900 \mathrm{~K}$ demonstrate a stronger negative temperature coefficient behavior for the FACE F gasoline having lower octane sensitivity. In addition, RCM pressure profiles under two-stage ignition conditions illustrate that the magnitude of low-temperature heat release (LTHR) increases with decreasing fuel octane sensitivity. However, intermediate-temperature heat release is shown to increase as fuel octane sensitivity increases. Various surrogate fuel mixtures were formulated to conduct chemical kinetic modeling, and complex KAUST multicomponent surrogate mixtures were shown to reproduce experimentally observed trends better than simpler two- and three-component mixtures composed of $n$-heptane, iso-octane, and toluene. Measurements in a Cooperative Fuels Research (CFR) engine demonstrated that the KAUST multicomponent surrogates accurately captured the antiknock quality of the FACE gasolines. Simulations were performed using multicomponent surrogates for FACE F and G to reveal the underlying chemical kinetics linking fuel composition with ignition characteristics. A key discovery of this work is the kinetic coupling between aromatics and naphthenes, which affects the radical pool population and thereby controls ignition.
\end{abstract}

\section{DRAFT FOR COMBUSTION AND FLAME}




\section{Introduction}

Gasoline fuels are widely used in automobiles powered by spark ignition (SI) engines. Stringent regulations on fuel economy and emissions are motivating engine downsizing and boosting [1-3]. Increasing the intake pressure (i.e., boosting) via turbocharging typically results in higher in-cylinder temperatures; however, by the use of intercooling and exhaust gas recirculation, the intake temperatures for a given pressure are lower resulting in increased engine efficiency [2,3]. In such modern engines, the conventional antiknock quality metrics of research octane number (RON) [4] and motor octane number (MON) [5] are less relevant. As explained by Kalghatgi [6-8], the MON test is conducted at a higher intake temperature and a lower intake pressure than the RON test, while recent engines operate at condition that are notably "beyond RON" conditions. That is, the unburned gas mixture temperature for a given pressure is lower in modern engines than it is in the RON test condition [6-8]. To better characterize a fuel's antiknock quality, Kalghatgi proposed the Octane Index (OI) metric, wherein $\mathrm{OI}=\mathrm{RON}-\mathrm{KS}$; $\mathrm{K}$ is an empirical constant related to the engine operating conditions and $\mathrm{S}=\mathrm{RON}-\mathrm{MON}$ is the octane sensitivity of the fuel [9,10]. Modern engines are moving towards conditions wherein $\mathrm{K}$ is increasingly negative [2], so a fuel with greater octane sensitivity has a higher $\mathrm{OI}$ and can allow engines to operate more efficiently $[1,7]$.

A fuel's antiknock quality is determined by its ability to avoid auto-ignition in the cylinder end-gas region [8]. Fundamental homogeneous gas-phase ignition delay time experiments can be used to investigate fuel's antiknock quality. Various experimental studies have been conducted to understand ignition of fully blended gasoline fuels using shock tubes (STs) [11,12] and rapid compression machines (RCMs) [12-14]. The studies [11,13,14] focused on a test gasoline denoted RD387 that is similar to commercial US gasoline. In addition to experiments, chemical kinetic modeling of gasoline ignition is necessary for engine simulations. Developing such models for a fully formulated gasoline is intractable due to its complex molecular composition [15]. Thus, surrogate fuels comprising a limited number of components mixed in proportions to match gasoline fuel target properties are utilized for chemical kinetic modeling. Previous gasoline surrogate formulation approaches are discussed in the literature [15-27], and further details on their relevance to this work are discussed later. 
Also relevant to the current study are fundamental studies on gasoline surrogate mixtures. These include primary reference fuel (PRF, $n$-heptane/iso-octane), toluene reference fuel (TRF, toluene/nheptane), toluene primary reference fuel (TPRF, toluene/n-heptane/iso-octane), and multicomponent mixtures. Several studies relate the homogenous gas-phase ignition delay characteristics of surrogates with octane numbers (RON and MON) measured in engines. Bradley et al. [28,29] and Mehl et al. [16,30] showed that a fuel mixture's RON and MON can be predicted from chemical kinetic simulations. Recently, Badra et al. [31] refined such correlations to predict octane numbers for various TPRF mixtures. Andrae and coworkers [23,32] used chemical kinetic simulations and HCCI engine experiments to relate fuel ignition characteristics to RON and MON for PRF and TPRF surrogates and their mixtures with ethanol and di-isobutylene. Similar approaches were applied in other studies $[21,26,33]$.

Despite past experimental and chemical kinetic modeling studies on ignition of gasoline fuels and their surrogates, there is dearth in understanding of the effects of gasoline properties (e.g., RON, MON, S, composition, etc.) on ignition characteristics. To date, the majority of fundamental combustion studies $[13,14,16,17,27]$ were conducted on a single non-oxygenated gasoline fuel (i.e., RD387). Recognizing the need to understand the effects of gasoline properties, a campaign was initiated by King Abdullah University of Science and Technology (KAUST), Lawrence Livermore National Laboratory (LLNL), Rensselaer Polytechnic Institute (RPI), and University of Connecticut (UCONN) to study the ignition characteristics of specially formulated FACE [34] (Fuels for Advanced Combustion Engines) gasolines. Sarathy et al. [12] studied the ignition characteristics of two FACE gasolines, FACE A and FACE C, with RON and MON $\sim 84$ thus $S \sim 0$. They showed that a simple primary reference fuel surrogate mixture, PRF 84 (84 vol\% iso-octane and 16 vol\% $n$-heptane), experimentally matched the ignition characteristics of the target FACE gasolines, except at lower ( $<750 \mathrm{~K})$ temperatures and higher pressures (20 and $40 \mathrm{~atm}$ ). Their simulations demonstrated that multicomponent surrogate mixtures could reproduce the experimentally observed ignition characteristics of FACE A and C better than a PRF 84 surrogate mixture.

The current study aims to further investigate the effects of gasoline properties using two nonoxygenated high-octane FACE blends, FACE F and FACE G. Table 1 compares general properties of these two gasoline blends. These gasoline fuels exhibit similar antiknock index $(\mathrm{AKI}=[\mathrm{RON}+\mathrm{MON}]$ / 2) values, while their sensitivities differ by $\sim 5.5$ units. Thus, comparing the ignition characteristics of 
these two blends can elucidate the effects of fuel octane sensitivity on ignition characteristics. Furthermore, their AKI values are close to those of pump-grade US gasolines while many properties of FACE G are close to those of the European gasolines (e.g., RON, octane sensitivity, aromatic content, etc.). Experimental measurements in STs and RCMs are accompanied by surrogate fuel formulation and chemical kinetic modeling to provide insights into the effects of gasoline composition on octane sensitivity and ignition characteristics. Experimental measurements in the CFR engine are also presented to validate the multicomponent surrogates formulated for the FACE gasolines. To our knowledge, this is the first study to systematically investigate the effect of gasoline octane sensitivity on ignition characteristics in fundamental devices (e.g., STs and RCMs) across a range of pressures, temperatures, and equivalence ratios.

Table 1 - General properties of FACE F and G [34]

\begin{tabular}{lll}
\hline Property & FACE F & FACE G \\
\hline AKI & 91.6 & 91.3 \\
Octane Sensitivity & 5.6 & 11.0 \\
$n$-Paraffins (mol \%) & 4.8 & 7.9 \\
iso-Paraffins (mol \%) & 61.0 & 38.3 \\
Cycloparaffins (mol \%) & 15.8 & 14.1 \\
Aromatics (mol \%) & 8.4 & 31.8 \\
Alkenes (mol \%) & 10.0 & 7.9 \\
\hline
\end{tabular}

\section{Experimental and Computational Methods}

This section describes experimental and computational methods employed in this study. The experiments include ignition delay measurements conducted for FACE F and FACE G in STs and an RCM. The range of experimental conditions is presented in Table 2. The fuel characterization, palette of surrogate species, chemical kinetic model development, and surrogate fuel formulation are also presented in this section.

Table 2 - Range of experimental conditions for FACE F and G.

\begin{tabular}{lllll}
\hline Facility & Fuel & Equivalence ratio $\phi$ & Temperature range (K) & Pressure (atm) \\
\hline UCONN RCM & F and G & 0.5 and 1.0 & $650-940$ & 20 and 40 \\
KAUST ST & F & 0.5 and 1.0 & $743-1235$ & 20 and 40 \\
RPI ST & G & 1.0 & $779-1168$ & 20 and 40
\end{tabular}




\subsection{High pressure shock tube experiments}

Ignition delay time measurements were carried out in two separate high-pressure shock tube (HPST) facilities at KAUST and RPI. The RPI shock tube measurements were performed behind reflected shock waves using experimental methods previously reported [35,36]. Similar experiments were performed at the KAUST HPST [37] with a $6.6 \mathrm{~m}$ long driven section and an inner diameter of $10 \mathrm{~cm}$. The experiments were performed at the nominal pressures of 20 and $40 \mathrm{~atm}$, equivalence ratios of $\phi=$ 0.5 and 1.0, and temperatures ranging from 740 to $1270 \mathrm{~K}$. At RPI, experiments were performed for stoichiometric FACE F/air mixtures at 20 and 40 atm, stoichiometric FACE G/air mixtures at 40 atm, and lean FACE G/air mixtures at 20 and 40 atm. At KAUST, experiments were performed for stoichiometric FACE G/air and FACE F/air mixtures at 20 and 40 atm and lean FACE F/air mixtures at 20 and 40 atm. Air was defined as pure (99.995\%) $\mathrm{O}_{2}$ and $\mathrm{N}_{2}$ at a molar ratio of 1 to 3.76. Reactant mixtures were prepared by direct injection of fuels into a heated mixing vessel. Following vaporization of the fuel, $\mathrm{N}_{2}$ and then $\mathrm{O}_{2}$ were added to the mixing vessel from compressed gas cylinders; reactant mixture molar fractions were controlled via partial pressure. The experimental conditions were chosen for relevance to internal combustion engines, accessibility in the shock tube, and to provide some overlap between the RPI and KAUST shock tube facilities. The ignition delay time is defined as the time interval between the arrival of the reflected shock wave and the onset of ignition, as determined by extrapolating the steepest rise in both pressure and $\mathrm{OH}^{*}$ chemiluminescence to their respective preignition zero signal. The uncertainties in reflected shock temperature and pressure are less than $\pm 1 \%$, and the estimated uncertainty in ignition delay time is $\pm 20 \%$. The non-ideal pressure rise behind the reflected shock is around $+3 \%$ per millisecond due to viscous shock attenuation, and this non-ideality is accounted for in numerical simulations. Example pressure traces for long ignition delay time measurements are illustrated in Figure S1 (RPI and KAUST) in the Supplementary Material. The experimental data is also appended as Supplementary Material

\subsection{Rapid compression machine experiments}

Ignition delay measurements were also performed in a rapid compression machine at UCONN. The RCM used in the current study employs a pneumatically driven creviced piston for the compression 
event. Further details about the geometry and design of the RCM can be found in Das et al. [38]. Stoichiometric and lean mixtures of FACE F/air and FACE G/air were studied at nominal pressures of 20 and 40 atm and temperatures ranging from 650 to $940 \mathrm{~K}$. Homogeneous fuel-oxidizer mixtures were prepared in a stainless steel chamber equipped with heaters and a magnetic stirrer. The liquid fuels were gravimetrically measured and injected into the mixing chamber. Ultra-high purity (>99.99\%) nitrogen and oxygen supplied by Airgas ${ }^{\circledR}$ were used for oxidizer mixtures. The oxidizer gases at a molar ratio of $\mathrm{N}_{2}: \mathrm{O}_{2}=3.76: 1$ were manometrically introduced to the mixing chamber. After filling the mixing chamber with fuel and oxidizer gases, the heaters and magnetic stirrer were activated for 3 hours to attain the desired preheat temperatures and homogeneity. After preparing a homogeneous test mixture, the reaction chamber was filled with test charge and compressed to the desired compressed pressure. The preheat temperature $\left(T_{0}\right)$, intake charge pressure $\left(P_{0}\right)$, and compression ratio were varied to attain the desired conditions at the end of compression (EOC), in terms of compressed temperature $\left(T_{\mathrm{C}}\right)$ and compressed pressure $\left(P_{\mathrm{C}}\right)$. The compressed temperature $\left(T_{\mathrm{C}}\right)$ is deduced from the measured pressure trace using the adiabatic core hypothesis,

$$
\int_{T_{0}}^{T_{c}} \frac{\gamma}{\gamma-1} \frac{\mathrm{d} T}{T}=\ln \left(\frac{P_{c}}{P_{0}}\right),
$$

where $\gamma$ is the specific heat ratio of the test charge. The uncertainty in the deduced compressed temperatures is $\pm 5 \mathrm{~K}$, with the major contributor to the uncertainty being the uncertainty in the initial temperature measurement using a thermocouple which is about $\pm 1.5 \mathrm{~K}$.

Figure $\mathrm{S} 2$ shows the definition of first stage ignition delay $\left(\tau_{1}\right)$ and total ignition delay $(\tau)$. Ignition delays were defined relative to the EOC (defined as $t=0$ ), which was identified as the point corresponding to the maximum of the pressure during the compressions stroke. Ignition delays, both $\tau_{1}$ and $\tau$, were defined as the time difference between EOC and the local maxima of the derivative of the pressure.

Figure S3 shows the reproducibility of the experimental data. A minimum of five consecutive runs were conducted and the pressure trace close to the mean from the scatter was used to report ignition delays. The experimental uncertainty in the ignition delay measurements is about $10 \%$ of the reported values with the uncertainty arising from the scatter in the experimental pressure traces. Furthermore, for each compressed condition, the corresponding inert run was taken by replacing oxygen with 
nitrogen in the oxidizer mixture. Inert runs were acquired to infer the heat loss characteristics needed for simulations [39].

\subsection{Fuel characterization and surrogate palette}

The compositions of FACE F and G fuels (supplied by Conoco Phillips Chemical Company) were determined using detailed hydrocarbon analysis (DHA) at Saudi Aramco's Research and Development Center, following the standard test methods of ASTM D6733 and D6730 [40]. The vendor's certificate of analysis also provided a distribution of hydrocarbon groups in the PIONA matrix, such as $n$ paraffins (n-alkanes), iso-paraffins (iso-alkanes), olefins (alkenes), naphthenes (cycloalkanes), and aromatics. A good agreement was observed between the vendor's PIONA and the one presented herein. Furthermore, the DHA method was extended for complete isomer resolution of all species in the gasoline sample. In this way aromatics, iso-paraffins, olefins, and naphthenes of the same carbon number could be uniquely identified. In total, more than 100 species were identified and quantified in each gasoline sample, which is $>99.5 \%$ of all hydrocarbons in each sample. The complete DHA report is provided as Supplementary Material.

The DHA results for FACE F and $G$ were utilized to select a palette of species for surrogate fuel formulation. Following previous work [12,20], the palette for FACE A and C was adopted here. The DHA results revealed that $n$-butane and $n$-heptane are suitable surrogates for the range of paraffins in FACE F and G, while 2-methylbutane (iso-pentane), 2-methylhexane, and 2,2,4-trimethylpentane (isooctane) appropriately represent the iso-paraffins. As noted in Table 1, FACE F and G have significant fractions of aromatics, naphthenes, and olefins, in contrast to the highly paraffinic FACE A and C gasolines. Toluene and 1,2,4-trimethylbenzene were included in the palette, as these two components account for $41 \mathrm{~mol} \%$ of the total aromatics in FACE G. The remaining aromatics in FACE G and those in FACE F are other trimethylbenzene and xylene isomers, whose reactivity can be approximated by appropriate mixtures of toluene and 1,2,4-trimethylbenzene. The olefinic content of FACE G is primarily 2-methylpentene (>99 mol\%), while FACE F is composed of various $\mathrm{C}_{5}$ and $\mathrm{C}_{6}$ olefins. Chemical kinetic models for various olefins are unavailable, so 1-hexene [41] was selected as its carbon number and double bond position are representative of the olefins in FACE F and G. Finally, cyclopentane was included in the palette because it comprises $92 \mathrm{~mol} \%$ and $75 \mathrm{~mol} \%$ of the naphthenic content in FACE F and G, respectively. The complete surrogate palette for FACE F and G is shown in 
Figure 1 with relevant physical and chemical kinetic properties for each species presented in Table S1 in the Supplementary Material.

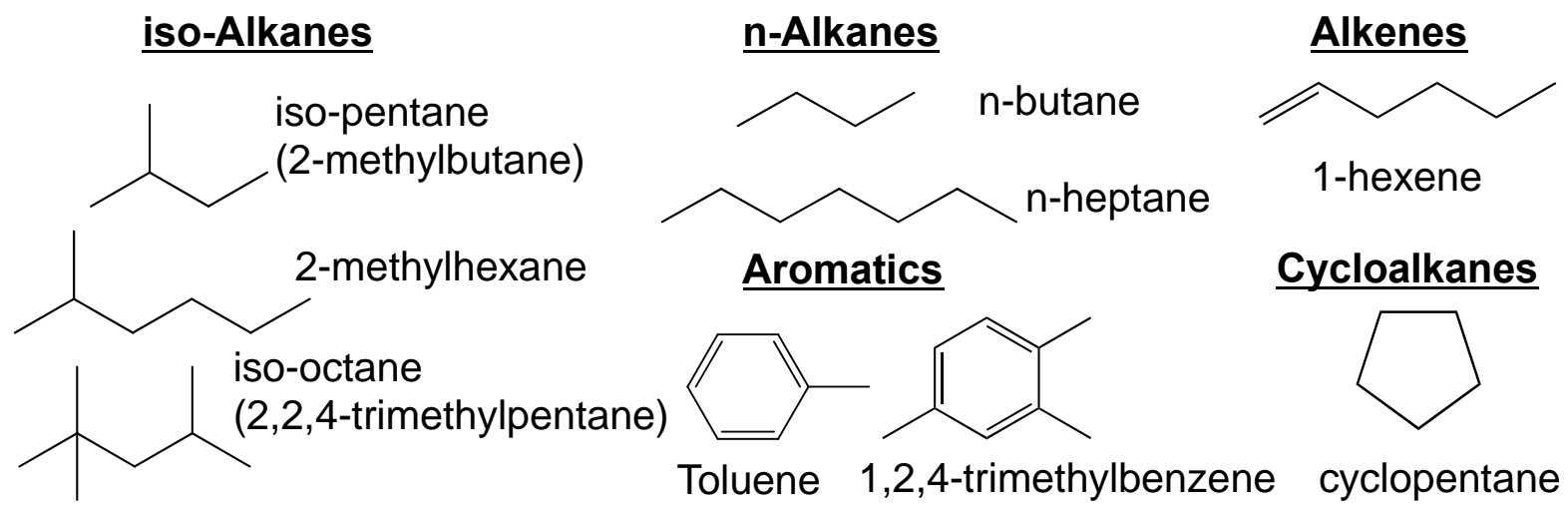

Figure 1. Palette of surrogate fuel components.

\subsection{Chemical kinetic model development}

Following the identification of the surrogate palette, a chemical kinetic model was developed to simulate the ignition of surrogate fuel mixtures. We started with the model for FACE A and C gasolines [12] based on the LLNL gasoline surrogates model [16,42]. This model was updated with the AramcoMech 1.3 [43] $\mathrm{C}_{0}-\mathrm{C}_{4}$ base chemistry, enabling simulations of mixtures comprising iso-pentane [44], 2-methylhexane [45,46], iso-octane [42], $n$-butane [47], $n$-heptane [42], toluene [42,48], and 1hexene [41,42]. New chemical kinetic sub-models for cyclopentane and 1,2,4-trimethylbenzene were then added to the primary gasoline model. The comprehensive development and validation of these sub-models will be presented in separate manuscripts. Briefly, the 1,2,4-trimethylbenzene model was based on the alkylaromatics kinetic models developed by LLNL and NUIG [49-52] and the xylene isomers model by LLNL [53]. During this process, the toluene sub-model was also updated based on studies from Metcalfe et al. [54] and Zhang et al. [48]. The rate rules proposed by Zhang et al. for toluene [48] were also used to improve the models for 1,2,4-trimethylbenzene and xylene isomers. A detailed chemical kinetic model for cyclopentane comprising low- and high-temperature reaction classes was developed by KAUST and LLNL [55,56] and added to complete the model for all 9 gasoline surrogate components. The present gasoline surrogate kinetic model includes 2,315 species and 10,079 reactions. At the time of publication, this gasoline surrogate kinetic model will be the most comprehensive available in the literature and represents the state-of-the-art. However, it should be noted that the model does not incorporate several recent development in combustion chemistry of $\mathrm{C}_{3}$ 
and $\mathrm{C}_{4}$ hydrocarbons [37,57,58], pentane isomers [59,60], and n-hexane [61] or extended low temperature reaction mechanisms [62,63].

All ignition delay simulations were performed using CANTERA [64] on CLOUDFLAME [65,66]; CHEMKIN PRO [67] was also utilized to verify that the CANTERA simulations were accurate and to perform sensitivity analyses. All simulations utilized the homogeneous batch reactor module with variable volume profiles to account for relevant facility effects. The numerical solver may fail when Ar and $\mathrm{H}_{2} \mathrm{O}$ are not present in the reactant composition due to chemical stiffness in third body reactions involving these species as collision partners. To obtain convergence, a small amount of $\mathrm{Ar}$ and $\mathrm{H}_{2} \mathrm{O}$ (e.g., 1 ppb) was added to the initial composition. The chemical kinetic model has been developed and tested using a commercial version of CHEMKIN PRO, so researchers using other codes are encouraged to contact the authors when facing compatibility issues.

\subsection{Target properties and surrogate fuel formulation}

The surrogate species and chemical kinetic model enable gasoline combustion simulations, provided they are mixed in the correct proportions to match specific gasoline fuel target properties. In this study, various gasoline surrogates are proposed and simulated to determine the suitability of each in emulating ignition characteristics of FACE F and G. Many physical and chemical properties can be used as targets. Previous surrogate formulation studies for gasoline fuels have utilized AKI [16], octane sensitivity [16,21,25], H/C ratio [16,20,25,27], PIONA [16,25], RON [18,19,21,25,27], MON [18,19,21,25,27], carbon types [20], average molecular weight [20], and distillation curve/volatility $[18,20,27]$ as target properties. It is noted that target properties such as H/C ratio and PIONA permit accurate prediction of density and lower heating value (LHV) [20,25]. Table 3 presents the aforementioned target properties for FACE F and G. The DHA was used to calculate the PIONA distribution, carbon type distribution, $\mathrm{H} / \mathrm{C}$ ratio, and average molecular weight for FACE $\mathrm{F}$ and $\mathrm{G}$. The RON, MON, and density were measured by the supplier and also published recently by Cannella et al. [34]. The distillation curves were measured by Burger et al. [68] using the advanced distillation curve (ADC) approach described by Bruno et al. at NIST [69].

Various philosophies exist in determining the appropriate target properties and corresponding surrogate mixtures. Primary reference fuel (PRF) mixtures of $n$-heptane and iso-octane are the simplest surrogates to match the target gasoline's octane rating. It is impossible for a single PRF mixture to 
match both the RON and MON for a gasoline fuel having octane sensitivity, since PRFs are zero octane sensitivity by definition. Notwithstanding, the first candidate surrogate that we examined is PRF 91.5, a mixture of $91.5 \mathrm{vol} \%$ (90.6 mol\%) iso-octane and $8.5 \mathrm{vol} \%$ (9.4 mol\%) $n$-heptane (Table 4), that closely matches the AKI of both FACE F and G (Table 3). Ternary mixtures of $n$-heptane, iso-octane, and toluene [21,25,26] (TPRF) have been proposed to better match the RON, MON, and S of a target fuel. Our second candidate surrogates are TPRF mixtures formulated to match the RON and MON of FACE F and G, using the empirical correlations proposed by Kalghatgi et al. [21]. It should be noted that TPRF mixtures with matching RON and MON can match the engine performance characteristics of full boiling range gasolines in SI engines [21] and premixed compression ignition engines [70]. TPRF mixtures are also able to predict the onset of knock of gasolines using the Livengood-Wu integral [21]. For FACE F, the corresponding TPRF-F with matching RON and MON is composed of $49.1 \mathrm{~mol} \%$ iso-octane, $39.8 \mathrm{~mol} \%$ toluene, and $11.1 \mathrm{~mol} \% \mathrm{n}$-heptane (Table 4). The corresponding TPRF-G for FACE G is composed of $6.5 \mathrm{~mol} \%$ iso-octane, $78.2 \mathrm{~mol} \%$ toluene, and $15.3 \mathrm{~mol} \% \mathrm{n}$ heptane (Table 4). The TPRF surrogate mixtures have high concentrations of aromatic fractions compared to the FACE gasolines because only one component (i.e., toluene) is available to impart octane sensitivity. Multicomponent surrogate mixtures, on the other hand, can achieve octane sensitivity using various components (e.g., toluene, 1,2,4-trimethylbenzene, cyclopentane, and 1hexene). In addition to $\mathrm{RON}$ and $\mathrm{MON}$, additional target properties were selected to formulate multicomponent surrogate mixtures. Following previous work by LLNL [16], the PIONA, H/C ratio, and octane rating (AKI and $\mathrm{S}$ ) were targeted to develop 5-component surrogate mixtures for FACE F and G, denoted FGF-LLNL and FGG-LLNL, respectively. The compositions for each surrogate were determined by "numerically blending" the palette components to match the PIONA and octane numbers of the target FACE gasolines. The LLNL methodology correlates the simulated homogeneous gas-phase ignition delay time near 25 atm $825 \mathrm{~K}$ and the minimum slope in the negative temperature coefficient (NTC) region to the AKI and S of the target FACE gasolines, respectively [16]. In addition, mixtures with 7 and 8 components were formulated for FACE F and G, respectively, to match the RON, MON, PIONA, H/C ratio, carbon types, average molecular weight, density, and distillation characteristics using the computational methodology described by KAUST [20]. This methodology determines the optimal surrogate composition by minimizing an objective function representing the difference between target properties of the FACE gasolines and surrogate mixtures. For the formulation of these surrogates, the RON and MON were calculated based on linear relationship by mole fraction blending [71] of the various palette compounds. This linear by mole fraction blending scheme is 
suitable for toluene/n-heptane/iso-octane mixtures [72], but has not been tested for multicomponent mixtures. Ghosh et al. [73] have presented a more accurate non-linear by volume method, but the approach does not provide correction factors for the specific molecules in our surrogate palette. The distillation curve and density for surrogate mixtures were calculated using the REFPROP [74] simulation tool coupled to a MATLAB algorithm, as described by Mueller et al. [75]. The mole fractions of various carbon types in FACE F and G were determined based on classification in 14 different types (see Figure S4 in the Supplementary Material), as described by [75,76]. The compositions of surrogates formulated using the LLNL and KAUST methods are presented in Table 4. Comparisons of various surrogates with the target properties are discussed later. 
Table 3 - Target properties for FACE F and G and their surrogates

\begin{tabular}{|c|c|c|c|c|c|c|c|c|c|}
\hline Properties & $\begin{array}{l}\text { FACE } \\
\text { F } \\
\end{array}$ & $\begin{array}{l}\text { PRF } \\
91.5 \\
\end{array}$ & $\begin{array}{l}\text { TPRF- } \\
\mathrm{F}\end{array}$ & $\begin{array}{l}\text { FGF- } \\
\text { KAUST }\end{array}$ & $\begin{array}{l}\text { FGF- } \\
\text { LLNL } \\
\end{array}$ & $\begin{array}{l}\text { FACE } \\
\text { G }\end{array}$ & $\begin{array}{l}\text { TPRF- } \\
\text { G }\end{array}$ & $\begin{array}{l}\text { FGG- } \\
\text { KAUST }\end{array}$ & $\begin{array}{l}\text { FGG- } \\
\text { LLNL }\end{array}$ \\
\hline RON & $94.4^{1}$ & 91.5 & $94.4^{2}$ & $93.6^{3}$ & 93.8 & $96.8^{1}$ & $96.8^{2}$ & $95.2^{3}$ & 96.4 \\
\hline MON & $88.8^{1}$ & 91.5 & $89.1^{2}$ & $88.9^{3}$ & 89.5 & $85.8^{1}$ & $85.8^{2}$ & $87.9^{3}$ & 85.5 \\
\hline AKI & 91.6 & 91.5 & 91.8 & 91.5 & $91.6^{4}$ & 91.3 & 91.3 & 91.6 & $90.3^{4}$ \\
\hline $\mathrm{S}$ & 5.6 & 0 & 5.3 & 4.7 & $4.3^{4}$ & 11.0 & 11.0 & 7.3 & $10.9^{4}$ \\
\hline $\begin{array}{l}\text { Density } \\
\left(\mathrm{kg} / \mathrm{m}^{3}\right)\end{array}$ & 707 & 694 & 755 & 707 & 712 & 760 & 820 & 742 & 751 \\
\hline $\mathrm{H} / \mathrm{C}$ & 2.13 & 2.25 & 1.84 & 2.12 & 2.06 & 1.83 & 1.40 & 1.85 & 1.87 \\
\hline Avg. mol. wt. & 94.8 & 112.7 & 103.9 & 96.2 & 100.2 & 99.7 & 94.8 & 94.3 & 106.0 \\
\hline $\begin{array}{l}\text { Volume } \\
\text { recovered }(\%)\end{array}$ & $\mathrm{T}(\mathrm{K})^{5}$ & -- & -- & $\mathrm{T}(\mathrm{K})^{6}$ & $\mathrm{~T}(\mathrm{~K})^{6}$ & $\mathrm{~T}(\mathrm{~K})^{5}$ & -- & $\mathrm{T}(\mathrm{K})^{6}$ & $\mathrm{~T}(\mathrm{~K})^{6}$ \\
\hline 5 & 342 & -- & -- & 348 & 352 & 344 & -- & 343 & 359 \\
\hline 10 & 346 & -- & -- & 350 & 353 & 350 & -- & 345 & 361 \\
\hline 15 & 348 & -- & -- & 353 & 355 & 356 & -- & 348 & 363 \\
\hline 20 & 351 & -- & -- & 356 & 356 & 363 & -- & 351 & 366 \\
\hline 25 & 354 & -- & -- & 358 & 357 & 370 & -- & 355 & 369 \\
\hline 30 & 357 & -- & -- & 361 & 358 & 378 & -- & 359 & 371 \\
\hline 35 & 360 & -- & -- & 364 & 360 & 386 & -- & 363 & 375 \\
\hline 40 & 363 & -- & -- & 366 & 361 & 394 & -- & 367 & 378 \\
\hline 45 & 367 & -- & -- & 368 & 362 & 403 & -- & 371 & 381 \\
\hline 50 & 370 & -- & -- & 370 & 364 & 411 & -- & 376 & 385 \\
\hline 55 & 373 & -- & -- & 372 & 365 & 418 & -- & 381 & 389 \\
\hline 60 & 376 & -- & -- & 374 & 366 & 426 & -- & 386 & 393 \\
\hline 65 & 379 & -- & -- & 376 & 368 & 433 & -- & 391 & 398 \\
\hline 70 & 382 & -- & -- & 378 & 369 & 439 & -- & 397 & 405 \\
\hline 75 & 384 & -- & -- & 380 & 370 & 444 & -- & 406 & 415 \\
\hline 80 & 387 & -- & -- & 383 & 371 & 447 & -- & 417 & 426 \\
\hline 85 & 391 & -- & -- & 387 & 371 & 451 & -- & 428 & 435 \\
\hline
\end{tabular}

$52-1$ RON and MON measured based on ASTM standard methods [4,5]

$532 \quad 2$ RON and MON estimated using the correlations proposed in [21]

$55 \quad 3 \quad$ RON and MON estimated using linear by mole fraction blending [20,71]

$56 \quad 4$ RON and MON estimated using correlations from [16]

$575 \quad 5$ Advanced distillation curves measured in [68]

58

59

6 Advanced distillation curves estimated using REFPROP simulations [75,77] 
Table 4 - Mole percentages of components in each fuel surrogate

\begin{tabular}{llllllll}
\hline & PRF & TPRF- & FGF- & FGF- & TPRF-G & FGG- & FGG- \\
Palette compound & 91.5 & $\mathrm{~F}$ & KAUST & LLNL & & KAUST & LLNL \\
\hline$n$-Butane & 0 & 0 & 6.9 & 0 & 0 & 7.6 & 0 \\
2-Methyl butane & 0 & 0 & 9.8 & 0 & 0 & 9.5 & 0 \\
2-Methyl hexane & 0 & 0 & 7 & 0 & 0 & 9.8 & 0 \\
Cyclopentane & 0 & 0 & 15.8 & 14 & 0 & 15.3 & 14 \\
1,2,4-Trimethylbenzene & 0 & 0 & 8.4 & 0 & 0 & 21.1 & 31 \\
1-Hexene & 0 & 0 & 8.4 & 14 & 0 & 8.1 & 9 \\
$n$-Heptane & 9.5 & 11.1 & 0 & 7 & 15.3 & 0 & 8 \\
2,2,4-Trimethylpentane & 90.5 & 49.1 & 43.7 & 53 & 6.5 & 18 & 38 \\
Toluene & 0 & 39.8 & 0 & 12 & 78.2 & 10.6 & 0 \\
\hline
\end{tabular}

\subsection{CFR engine experiments}

Knock limited spark advance (KLSA) measurements for FACE $F$ and $G$ along with their multicomponent surrogates, FGF-KAUST and FGG-KAUST, were obtained with a modified Cooperative Fuel Research (CFR) engine. The carburetor was replaced with a port fuel injection (PFI) system placed very close to the intake valve. As a result, tests in strict accordance with ASTM D2699 and D2700 [4, 5] for RON and MON evaluations could not be performed. Alternatively, KLSA tests at conditions very close to standard test conditions, designated here as RON-like and MON-like conditions were carried out. Digital counter readings (DCR) on a CFR engine are empirically related to compression ratio [31], and values for RON-like tests of FACE gasolines and their surrogates were obtained from Table A4.1 in [4]. FACE F and G have RON 94.4 and 96.8, respectively, that corresponds to DCR values of $795(\mathrm{CR}=7.0)$ and 841 (7.3) at RON-like conditions. Similarly, for KLSA at MON-like conditions, DCR values of 725 (6.6) and 664 (6.3) were selected for FACE F and G, respectively, and these values were obtained from Table A4.1 in [5]. The same values of DCR were taken for surrogates corresponding to FACE gasolines that were analyzed. Details on engine specifications and test conditions are given in Table 5.

All surrogate fuels tested in the engine were blended gravimetrically, with the aid of precision balance. n-Butane, which has a boiling point of $-1{ }^{\circ} \mathrm{C}$, was liquefied at $\sim-20{ }^{\circ} \mathrm{C}$ in a cylinder cooled with dry ice. The liquefied n-butane was then added gravimetrically, and the surrogate blends were stored in a dry ice bath until tests were carried out. 
Table 5 - CFR engine specifications and conditions

\begin{tabular}{lcc}
\hline & RON-like & MON-like \\
\hline Engine type & Modified CFR F-1/F-2 \\
Number of cylinders & \multicolumn{2}{c}{1} \\
Bore $(\mathrm{mm})$ & \multicolumn{2}{c}{82.5} \\
Stroke (mm) & \multicolumn{2}{c}{114} \\
Connecting rod length (mm) & \multicolumn{2}{c}{254} \\
Compression ratio & $7.0^{1}$ & $6.6^{1}$ \\
Speed (rpm) & $7.3^{2}$ & $6.3^{2}$ \\
Fuel injection & 600 & $600^{3}$ \\
Intake temperature $\left({ }^{\circ} \mathrm{C}\right)$ & \multicolumn{2}{c}{ Port fuel injection } \\
Equivalence ratio & 52 & \multicolumn{2}{c}{149} \\
\hline
\end{tabular}

${ }^{1}$ FACE $\mathrm{F}$ and its surrogates

${ }^{2}$ FACE $\mathrm{G}$ and its surrogates

${ }^{3} \mathrm{MON}$ conditions require $900 \mathrm{rpm}$. Due to limitations of the variable-frequency drive, these tests were performed at $600 \mathrm{rpm}$

The knock intensity (KI) is defined as the maximum peak-to-peak variation in the high-pass filtered cylinder pressure. KI values for different spark timings for fuels and surrogates were obtained to characterize and compare their anti-knock quality. The values of KI were measured for FACE gasolines and their surrogates by advancing spark timing from 4 crank angle degree (CAD) after top dead center (aTDC) in steps of $2 \mathrm{CAD}$ to spark timings until severe knock (KI > 1.5 bar) was observed. Measurements were recorded for 190 cycles, each with a crank angle resolution of 0.1 CAD and cycle averaged values of KI have been reported with error bars corresponding to the standard deviation.

\section{Results and discussion}

\subsection{Shock tube ignition delay results}

Ignition delay times were measured in shock tubes at the nominal pressures of 20 and $40 \mathrm{~atm}$. The actual reflected shock pressures $\left(\mathrm{P}_{5}\right)$ varied in the range of 17.5 - $22.5 \mathrm{~atm}$ and $36.7-42.7 \mathrm{~atm}$. Figure 2 displays shock tube ignition delay times for FACE F and $G$ at 20 and 40 atm for lean and stoichiometric fuel/air mixtures. Stoichiometric FACE F/air measurements at 20 and $40 \mathrm{~atm}$ and FACE G/air experiments near 40 atm were independently conducted at both KAUST and RPI to crossvalidate the shock tube facilities. The results indicate excellent agreement between the two facilities at 
all studied conditions. Experimental data for the alkane-rich FACE A and C gasolines (AKI 84) obtained under similar conditions [12] are also presented in Figure 2 for comparison. For all pressures and equivalence ratios, all fuels display similar ignition delay times at temperatures above $900 \mathrm{~K}$ $(1000 / \mathrm{T}<1.1)$. These results indicate that the reactivity of fuel/air mixtures at high temperature conditions is largely insensitive to fuel composition, as four fuels with widely varying composition and octane numbers display comparable ignition delay times. However, in the temperature range of 715$850 \mathrm{~K}(1.18<1000 / \mathrm{T}<1.4)$, the higher octane gasolines, FACE F and G (AKI 91.5), display longer ignition delay times than the lower octane gasolines, FACE A and C (AKI 84). The shock tube data also suggest that FACE G displays longer ignition delay times than FACE F at higher pressures (40 atm) and lower temperatures $(\sim 750 \mathrm{~K}, 1000 / \mathrm{T} \sim 1.33)$, but these differences are within experimental uncertainty limits $( \pm 20 \%)$. In summary, the shock tube ignition delay results indicate that differences between the FACE gasolines are more prominent at lower temperatures and higher pressures. 

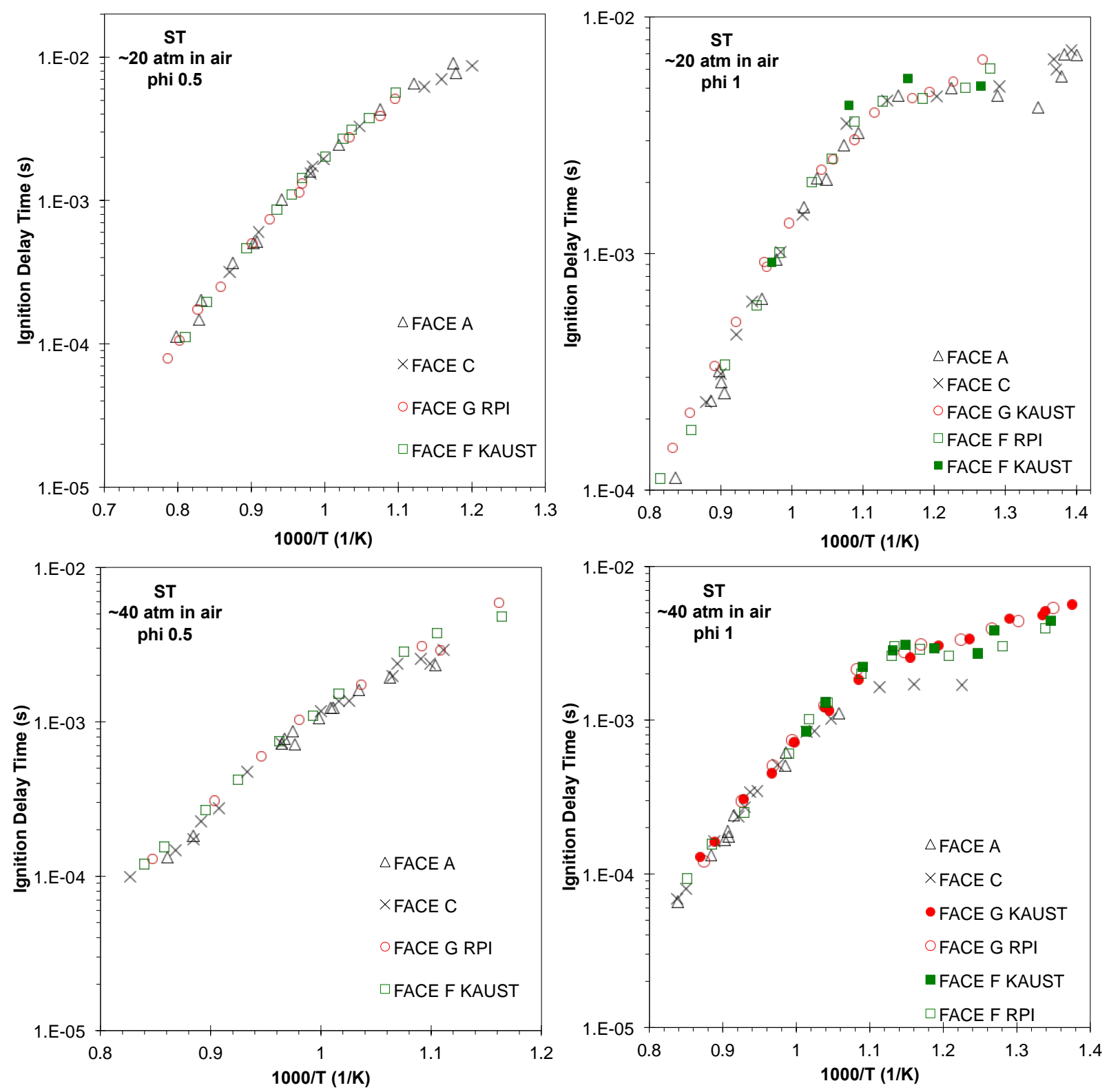

Figure 2. ST ignition delay data for FACE F and G at 20 and 40 atm for lean and stoichiometric conditions (FACE A and C data from [12]).

\subsection{RCM ignition delay results}

RCM measurements at 20 and 40 atm were conducted to study the ignition characteristics of lean and stoichiometric FACE F/air and FACE G/air mixtures at lower temperatures. Analysis of pressure traces (c.f. Figure S2) showed that both the FACE gasolines exhibited two-stage ignition response for temperatures lower than $750 \mathrm{~K}$ (low temperature regime (LTR) for 1000/T > 1.33). Distinct two stages of ignition were also observed at some compressed temperatures in the NTC regime $(750-833 \mathrm{~K}, 1.2<$ 
$1000 / T<1.33)$. For the compressed temperatures beyond the NTC regime, only single stage ignition was observed, and this regime has been defined as the intermediate-temperature regime (ITR, 833-900 $\mathrm{K}, 1.1<1000 / T<1.2)$ in the present study. Figure 3 compares ignition delays of FACE F and G gasolines at various test conditions investigated. Experimental data for FACE A and C gasolines obtained under similar conditions [12] are also presented. Figure 4 presents the first stage ignition delay times for the aforementioned fuels at various test conditions.
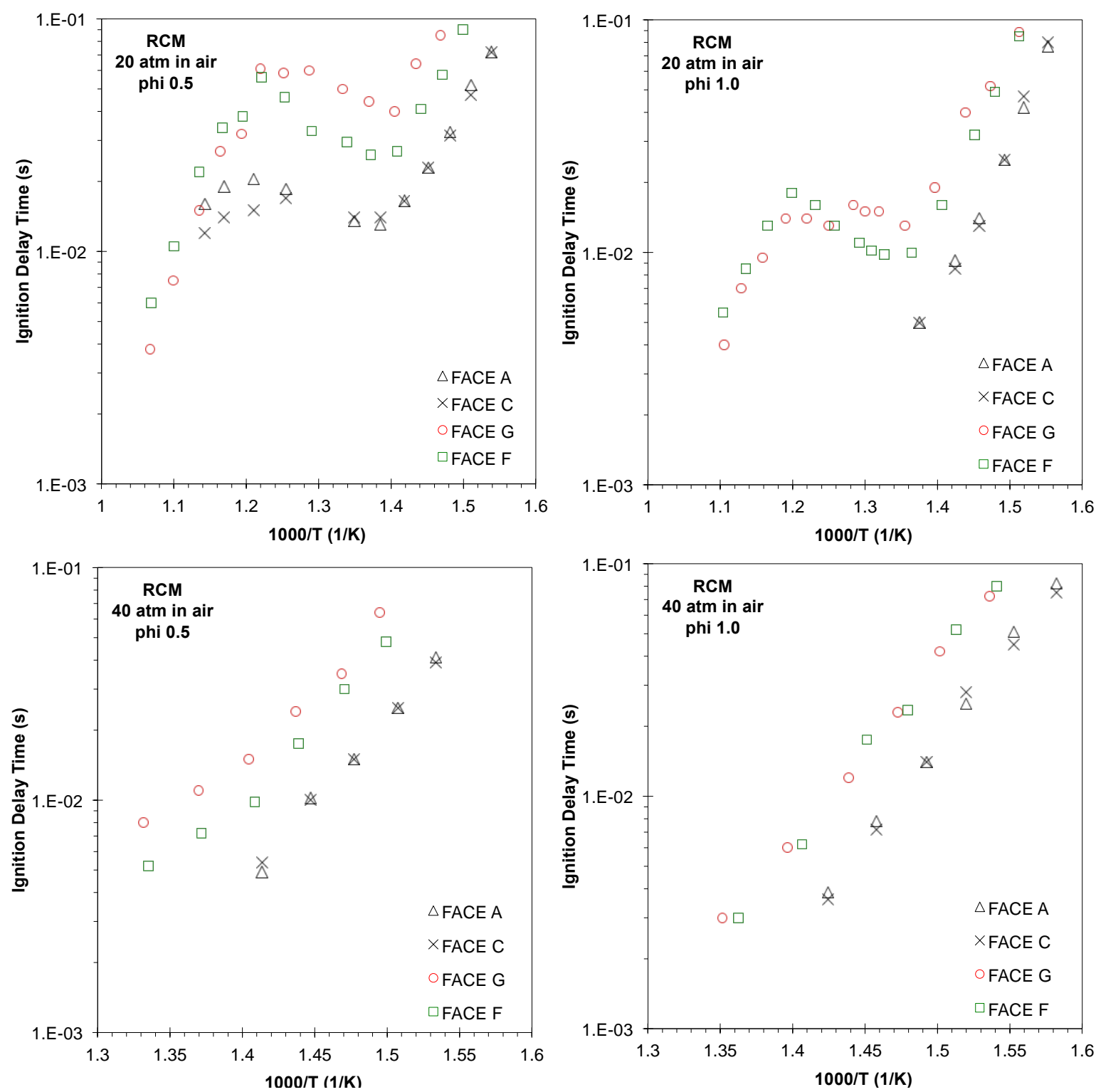

Figure 3. RCM ignition delay data for FACE F and $\mathrm{G}$ at 20 and 40 atm for lean and stoichiometric conditions (FACE A and C data from [12]). 
Several interesting trends can be observed in Figure 3 and Figure 4. First, the lower octane FACE A and C (AKI 84) gasolines display significantly shorter total and first stage ignition delay times compared to the higher octane FACE F and G (AKI 91.5). The RCM measurements clearly demonstrate the relationship between octane number and ignition propensity, i.e., higher octane number fuels display longer ignition delay times in LTR and NTC regime. The first stage ignition delays of both the FACE F and G gasolines are nearly identical for most of the test conditions, while some differences were observed for the test condition of $\phi=0.5$ and $20 \mathrm{~atm}$. The total ignition delays of FACE G were observed to be higher than those of FACE F in LTR at most of the test conditions, indicating that FACE $\mathrm{F}$ is relatively more reactive than FACE G for temperatures in LTR. It can also be observed in Figure 3 that the magnitude of the negative slope in the NTC regime is higher for FACE F when compared to that of FACE G, which is consistent with the observations made by Leppard [78] and Mehl et al. [16,30]. Leppard [78] observed that a fuel with lower octane sensitivity experienced a greater NTC effect because lower octane sensitivity fuels behave more like $n$-alkanes, which display pronounced NTC characteristics. Goldsborough et al. [79] also showed that a fuel with lower octane sensitivity displays higher negative slope in RCM experiments of two fuels with similar AKI (PRF 91 and TRF 91) but varying octane sensitivity. Furthermore, FACE G is more reactive in ITR at compressed temperatures greater than $800 \mathrm{~K}(1000 / T<1.25)$. It is well known that the end-gas temperatures under the RON test condition are lower than at the MON test condition $[8,78]$. The lower reactivity of FACE G in the LTR is consistent with its higher RON, while its higher reactivity in the ITR is consistent with its lower MON compared to FACE F. 

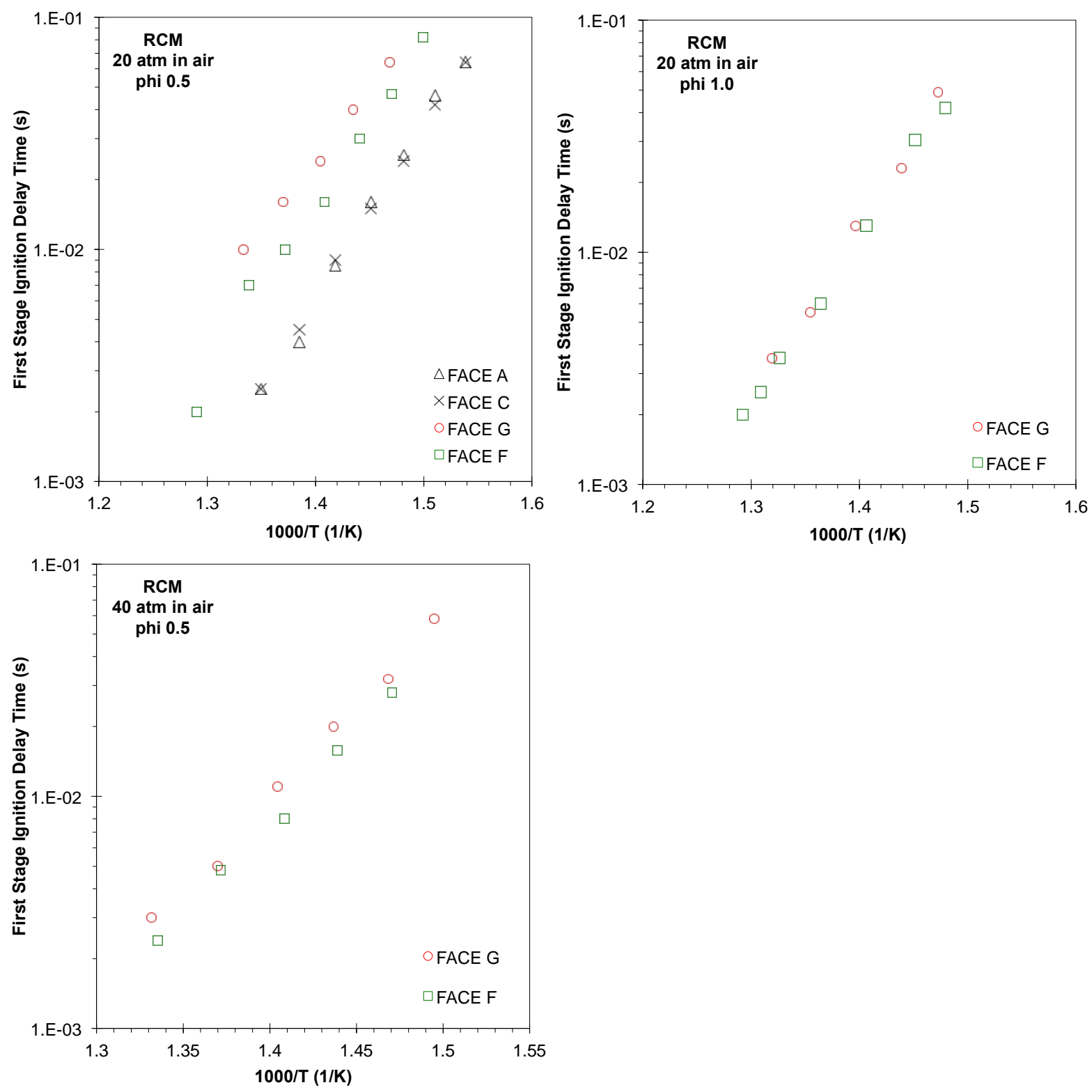

Figure 4. First stage RCM ignition delay data for FACE F and G at 20 and 40 atmfor lean and stoichiometric conditions (FACE A and C data from [12]).

\subsection{Effects of fuel octane sensitivity on RCM heat release}

RCM pressure trace evolutions during auto-ignition were compared to understand the effect of octane sensitivity on low-temperature heat release (LTHR) and intermediate-temperature heat release (ITHR). Figure 5 compares pressure traces at several compressed temperatures. It can be observed ( $a$ and $b$ ) that FACE F and G exhibit similar first stage induction times; however, FACE F displays a greater first stage pressure rise due to greater LTHR. This comparison shows that for fully blended gasoline fuels 
with similar AKI, a blend with lower octane sensitivity exhibits higher LTHR. Yang et al. [80] have shown that a fuel with higher LTHR exhibits higher $\phi$-sensitivity. Thus, the present results and those from [80] suggest that extending high-load operation for low-temperature combustion engines with help of partial fuel stratification and delayed combustion timing should be more easily achievable with fuels exhibiting lower octane sensitivity (at a fixed AKI).

Figure 5c shows the comparison of pressure trace evolutions for temperatures in the ITR, where first stage ignition is not observed. ITHR is identified by the differences between inert and reactive pressure traces. It can be seen that FACE G exhibits higher ITHR when compared to FACE F. These results suggest that a fuel blend with higher octane sensitivity exhibits higher ITHR at a specified AKI.

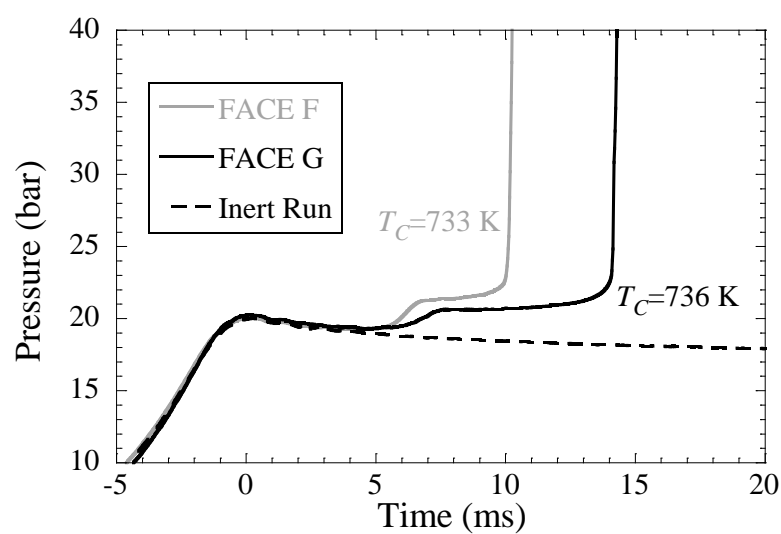

(a) $\phi=1, P_{C}=20$ bar

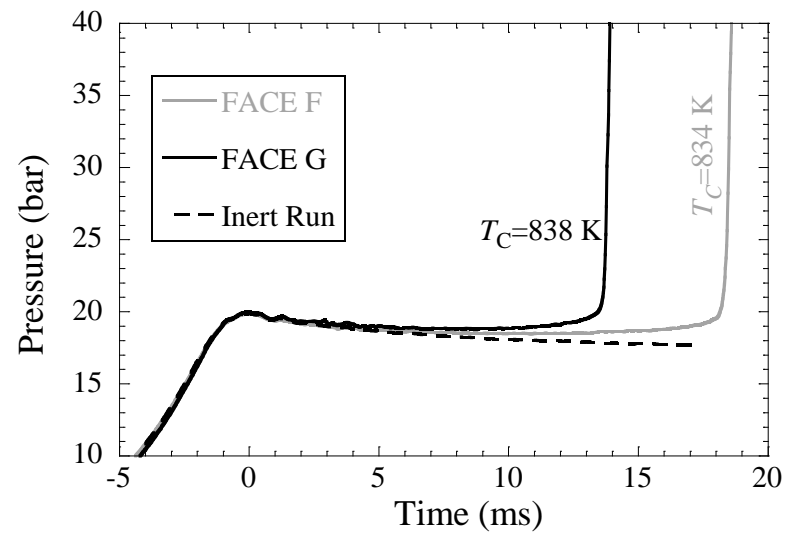

(c) $\phi=1, P_{C}=20$ bar

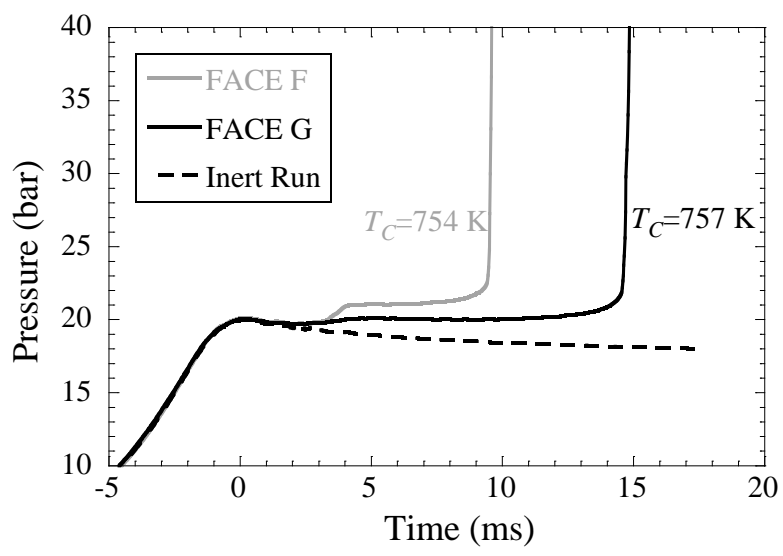

(b) $\phi=1, P_{C}=20$ bar 


\subsection{Surrogate fuel formulations results}

Surrogate mixtures were formulated for FACE F and G, in order to perform subsequent chemical kinetic modeling for the target FACE gasolines. Various surrogate formulation approaches were employed to ascertain the ability of each to reproduce specific target properties, as well as for their simulations to quantitatively and qualitatively reproduce the experimental ignition delay time measurements. A comparison of FACE gasoline target properties and those of various surrogates is presented in Table 3. In the following discussion, the surrogates are considered accurate if they can reproduce target properties within $10 \%$, an arbitrarily selected limit. It should be mentioned that the errors in surrogate formulations can be attributed to their composition, as well as to the methodology used to estimate target properties. The PRF 91.5, TPRF-F, and TPRF-G surrogates closely match the target octane ratings (e.g., AKI, RON, MON) and density. PRF 91.5 matches the H/C ratio of FACE F, but it has a higher $\mathrm{H} / \mathrm{C}$ ratio than FACE G, attributable to the larger aromatic fraction in the latter. The $\mathrm{H} / \mathrm{C}$ ratios for TPRF-F and TPRF-G are significantly lower than their respective FACE gasolines because excessive amounts of toluene are present to achieve target octane sensitivity. The distillation curves of these binary PRF and ternary TPRF surrogates are virtually flat between 372 and $384 \mathrm{~K}$, so are not presented in Table 3.

The target properties for multicomponent surrogates from LLNL and KAUST are presented in Table 3, Figure 6, and Figure 7. The octane ratings (RON, MON, S), density, average molecular weight, and $\mathrm{H} / \mathrm{C}$ ratios of LLNL and KAUST multicomponent surrogates closely match their respective target FACE gasolines. The PIONA and carbon types shown in Figure 6 and Figure 7 demonstrate that these surrogates accurately reproduce the chemical compositions and molecular characteristics of the FACE gasolines. It is expected that matching these chemical features will provide improved fidelity in predicting ignition delay times of the FACE gasolines. The volatility characteristics of the FACE gasolines and their multicomponent surrogates, as represented by their ADC plots, are also shown in Figure 6 and Figure 7 for FACE F and G, respectively. The simulated ADC values for FGF-LLNL and FGF-KAUST multicomponent surrogates match the measured values within $20 \mathrm{~K}$ across the entire distillation range, with the latter performing better than former. For FACE G, the FGG-LLNL surrogate matches the target ADC profile with a maximum deviation of $24 \mathrm{~K}$ ( $\sim \%$ error), while FGGKAUST displays a maximum discrepancy of $42 \mathrm{~K}(\sim 11 \%$ error). The discrepancies in FACE G volatility characteristics are due to the limited number of high boiling point and high octane components available for blending the surrogates. FACE $\mathrm{G}$ contains various high boiling point $\mathrm{C}_{8}-\mathrm{C}_{9}$ 
alkylaromatics, while the palette is limited to 1,2,4-trimethylbenzene (1,2,4-TMB). The FGG-KAUST volatility characteristics could be improved by increasing the amount of 1,2,4-TMB and decreasing the amount iso-alkanes; however, this would increase the RON and MON values significantly, as these are calculated using linear relationship mole fraction blending rule (RON and MON of 1,2,4-TMB are 110 and 101 , respectively).
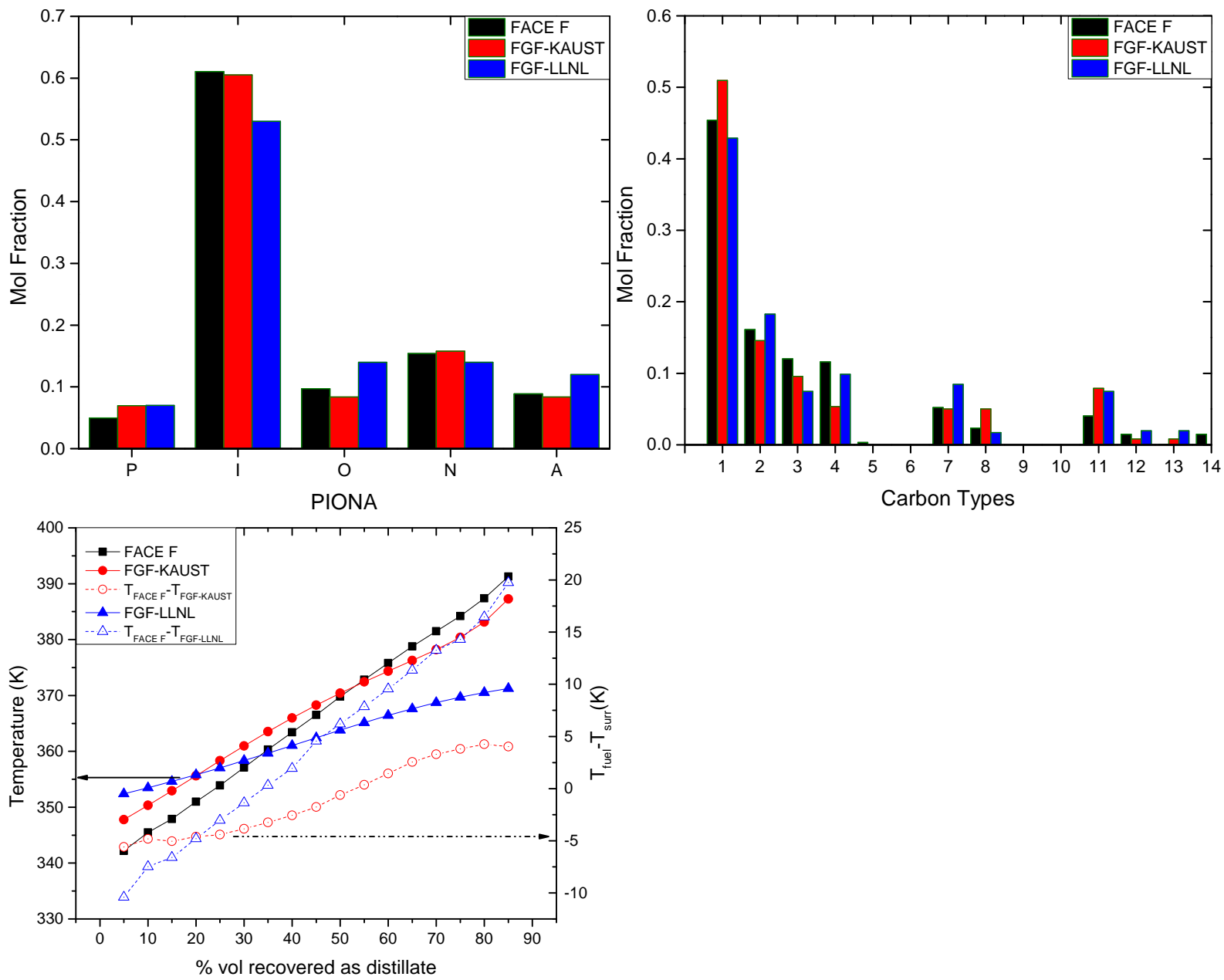

Figure 6. Comparison of PIONA, carbon types, and volatility (advanced distillation curve) for FACE F, FGF-LLNL, and FGF-KAUST. In bottom left plot, left y-axis corresponds to distillation temperatures and right y-axis corresponds to difference between values for FACE gasoline and surrogate. 

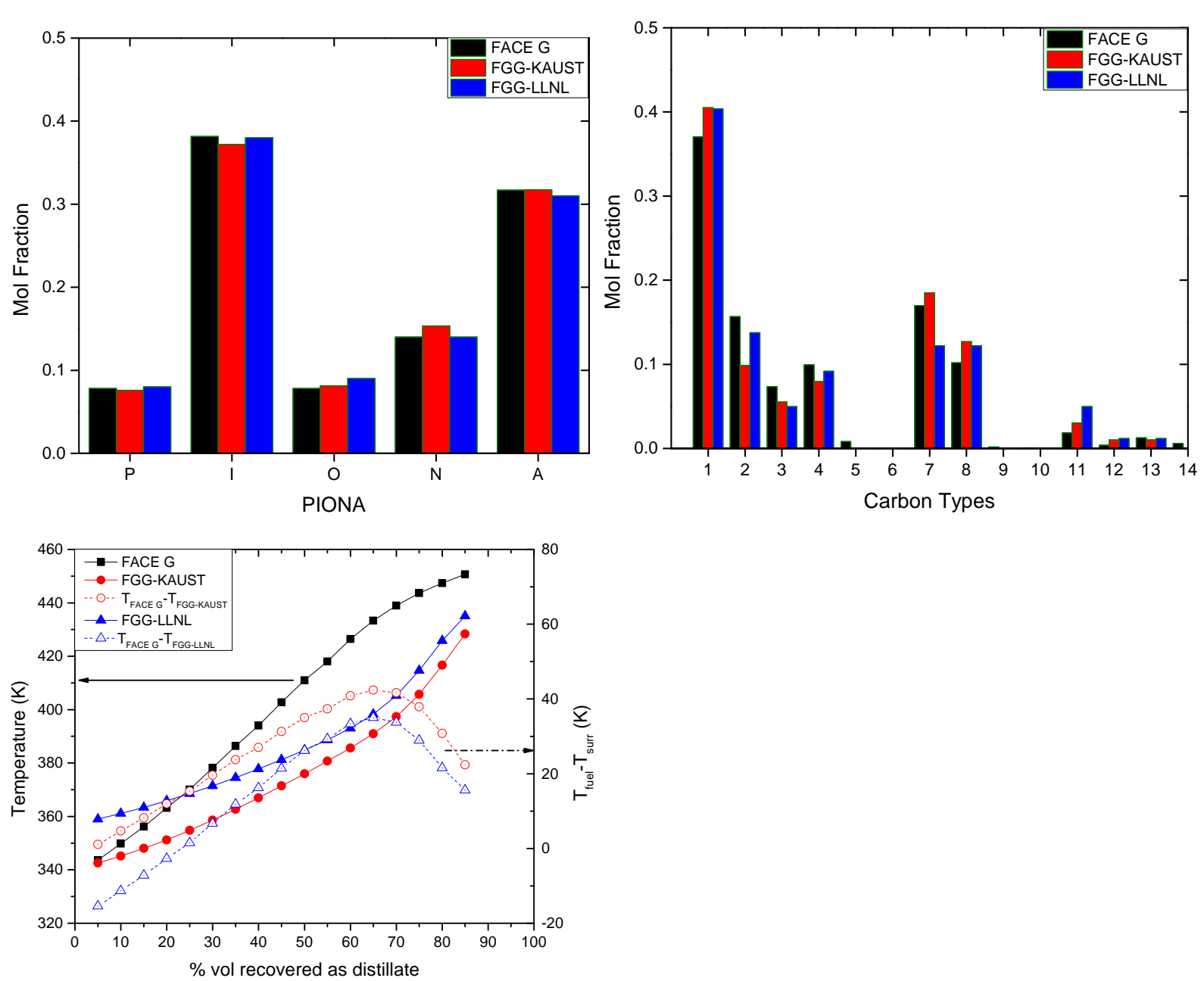

Figure 7. Comparison of PIONA, carbon types, and volatility (advanced distillation curve) for FACE G, FGG-LLNL, and FGG-KAUST. In bottom left plot, left y-axis corresponds to distillation temperature and right $\mathrm{y}$-axis corresponds to difference between values for FACE gasoline and surrogate

Figure 8 presents the KLSA measurements for FACE F, FACE G, FGF-KAUST, and FGG-KAUST performed in a modified CFR engine at RON-like and MON-like conditions. As mentioned previously, the experiments were not conducted in strict accordance with the ASTM testing methods for RON and MON. The result shows that FACE F and G display similar KI as the spark timing is advanced from 4 CAD aTDC to negative values. For all fuels, KI is minimal for spark timings greater than 0 CAD aTDC at RON-like conditions and $-4 \mathrm{CAD}$ aTDC at MON-like conditions. As the spark timing advances, KI increases significantly, indicating the onset of ignition in the end-gas (i.e., knock). 
Earlier spark timings result in increased KI because the end-gas region ahead of the propagating flame front achieves pressures and temperatures that promote ignition. The multicomponent surrogates for FACE F and G (i.e., FGF-KAUST and FGG-KAUST, respectively) accurately capture the qualtitative change in KI as a function of spark timing for their respective FACE gasoline under both RON-like and MON-like conditions. The KI values are also quantitatively reproduced within the experimental uncertainty limits. These results indicate that the multicomponent surrogates FGF-KAUST and FGGKAUST can capture experimentally measured knocking characteristics of FACE F and G, respectively. 

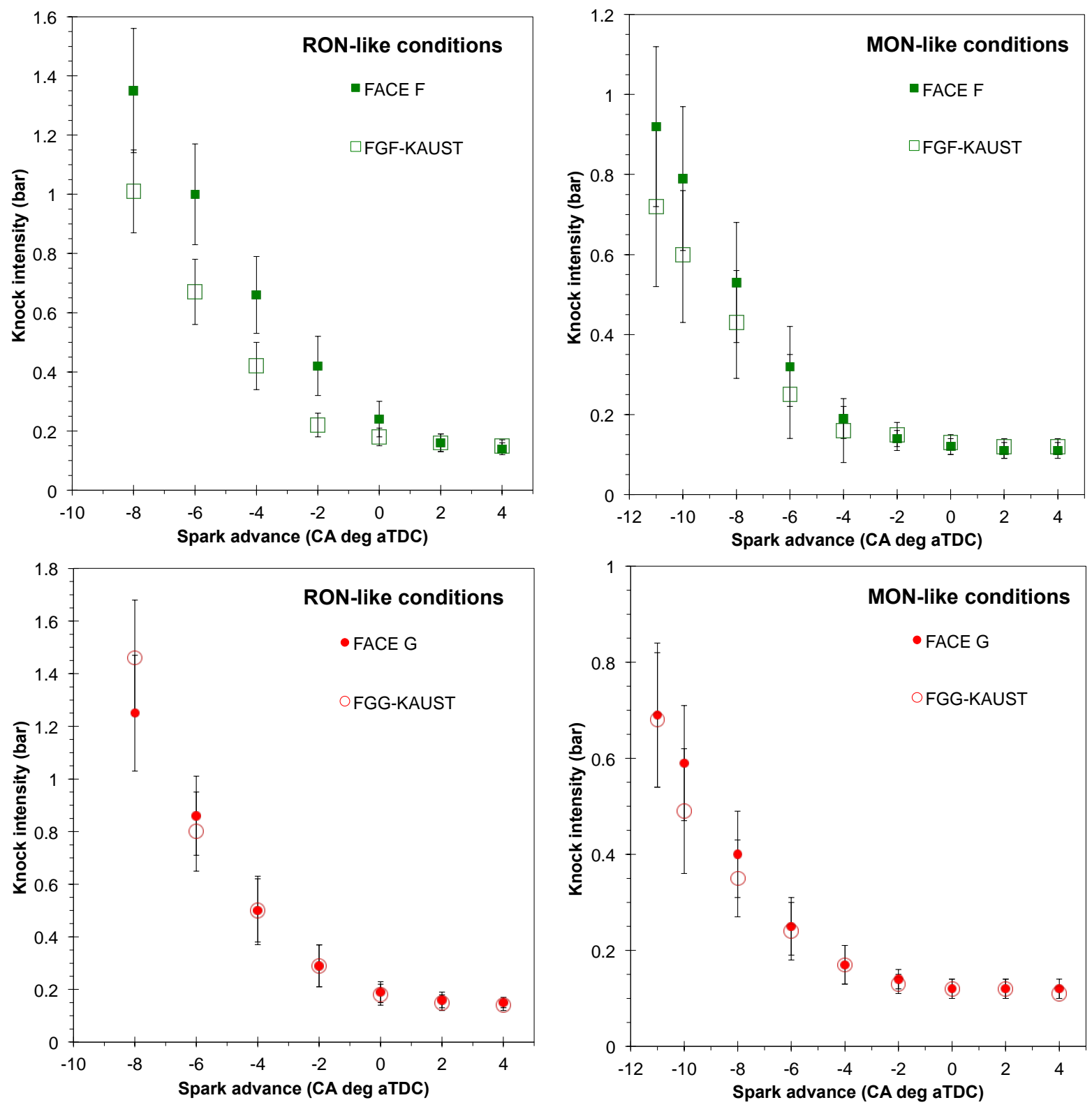

Figure 8. Knock limited spark advance (KLSA) measurements performed in the CFR engine for FACE F, FACE G, FGF-KAUST, and FGG-KAUST.

\subsection{Chemical kinetic modeling results}

Ignition delay times of FACE F and $\mathrm{G}$ were simulated using the proposed surrogate mixtures. The PRF, TPRF, and multicomponent surrogates were simulated using the gasoline surrogates kinetic model discussed previously. The following section compares the surrogate mixture simulations against the experimentally measured data, and aim to provide insights into the adequacy of various surrogate 
formulation methodologies. The results for FACE F are first presented, and then the comparisons for FACE G under ST and RCM conditions.

Simulated FACE F ignition delay times under ST conditions are presented in Figure 9. At all pressures and equivalence ratios, the data is well predicted by the various surrogate mixtures above $900 \mathrm{~K}$ $(1000 / T<1.11)$. At these high temperatures, all the surrogates (PRF 91.5, TPRF-F, FGF-LLNL, and FGF-KAUST) behave similarly and predict the experimental data within the measured uncertainty limits. Nevertheless, the simulations with multicomponent surrogates FGF-LLNL and FGF-KAUST are quantitatively closer to the measured data, with differences between the two being negligible. Below $900 \mathrm{~K}(1000 / T>1.11)$, the experimental data displays weak NTC behavior, which is qualitatively reproduced by all the surrogate mixture simulations. In the temperature regime (750-900 K, $1.11<1000 / T<1.33$ ), PRF 91.5 shows stronger NTC behavior than the other surrogates. In general, the multicomponent surrogates over-predict NTC ignition delay times in the ST by up to a factor of two, which is a kinetic modeling discrepancy that has been observed previously even for simpler mixtures (e.g., PRF 84) [12]. In summary, the FACE F ST ignition delay data are adequately simulated by any of the proposed surrogate mixtures because global reactivity at higher temperatures is largely insensitive to surrogate mixture composition. 

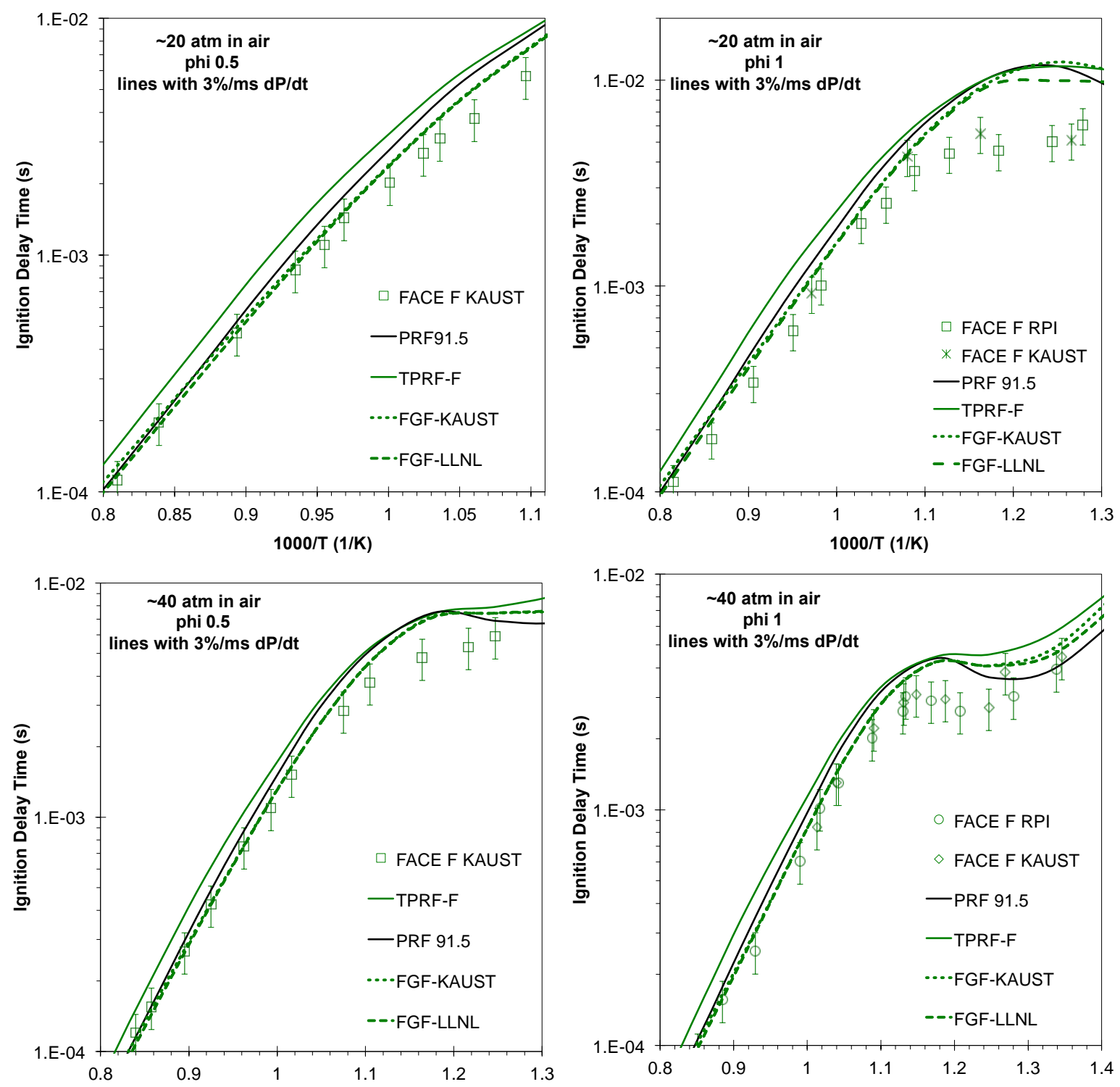

Figure 9. Simulated ST ignition delays for various FACE F surrogate mixtures. Symbols are experimental ST data and lines are simulations with $3 \%$ per $\mathrm{ms} \mathrm{d} P / \mathrm{d} t$. Error bars represent the experimental uncertainty of $\pm 20 \%$. Simulated ignition delays for FGG-KAUST and FGG-LLNL are indistinguishable at most conditions.

Simulated FACE F ignition delay times under RCM conditions are presented in Figure 10. As noted earlier, the RCM data extends to lower temperatures, permitting comparison of the various surrogates in the low and intermediate-temperature regimes. The experimental data of lean and stoichiometric conditions at $20 \mathrm{~atm}$ extends up to $900 \mathrm{~K}(1000 / T \sim 1.11)$, and the various surrogate mixtures adequately predict measured ignition delay times in this intermediate-temperature regime (833-900 K, 
$1.11<1000 / T<1.2)$. It should be noted that there is an overlap in experimental conditions between the ST and RCM for 20 atm stoichiometric fuel/air mixtures in the temperature range of 775-900 K; however, RCM measurements are consistently a factor of two slower than ST data at these conditions. The FACE F multicomponent surrogates are in better agreement with the RCM data at these conditions. At $20 \mathrm{~atm}$, the NTC regime extends from 710 to $833 \mathrm{~K}(1.2<1000 / T<1.41)$ for both the lean and stoichiometric conditions. In this regime, the PRF 91.5 surrogate simulations under-predict ignition delay times at stoichiometric conditions while performing well at lean conditions. The TPR-F surrogate over-predicts the measurements at both the lean and stoichiometric conditions, while the multicomponent FGF-LLNL and FGF-KAUST surrogates perform better, especially at the stoichiometric conditions. Measurements in the low-temperature regime $(<775 \mathrm{~K}, 1000 / T>1.29)$ were possible at both 20 and $40 \mathrm{~atm}$, and at these temperatures the measurements are under-predicted by the PRF 91.5 surrogate and over-predicted by the TPRF-F surrogate. The deviations between experiments and simulations are least for the multicomponent surrogates FGF-LLNL and FGF-KAUST with the latter being marginally better at 20 atm lean conditions. In summary, all the FACE F surrogate simulations qualitatively reproduce the effects of temperature, pressure, and equivalence ratio on the measured ignition delay times of FACE F, while the multicomponent FGF-LLNL and FGF-KAUST surrogate simulations display the best quantitative agreement. 

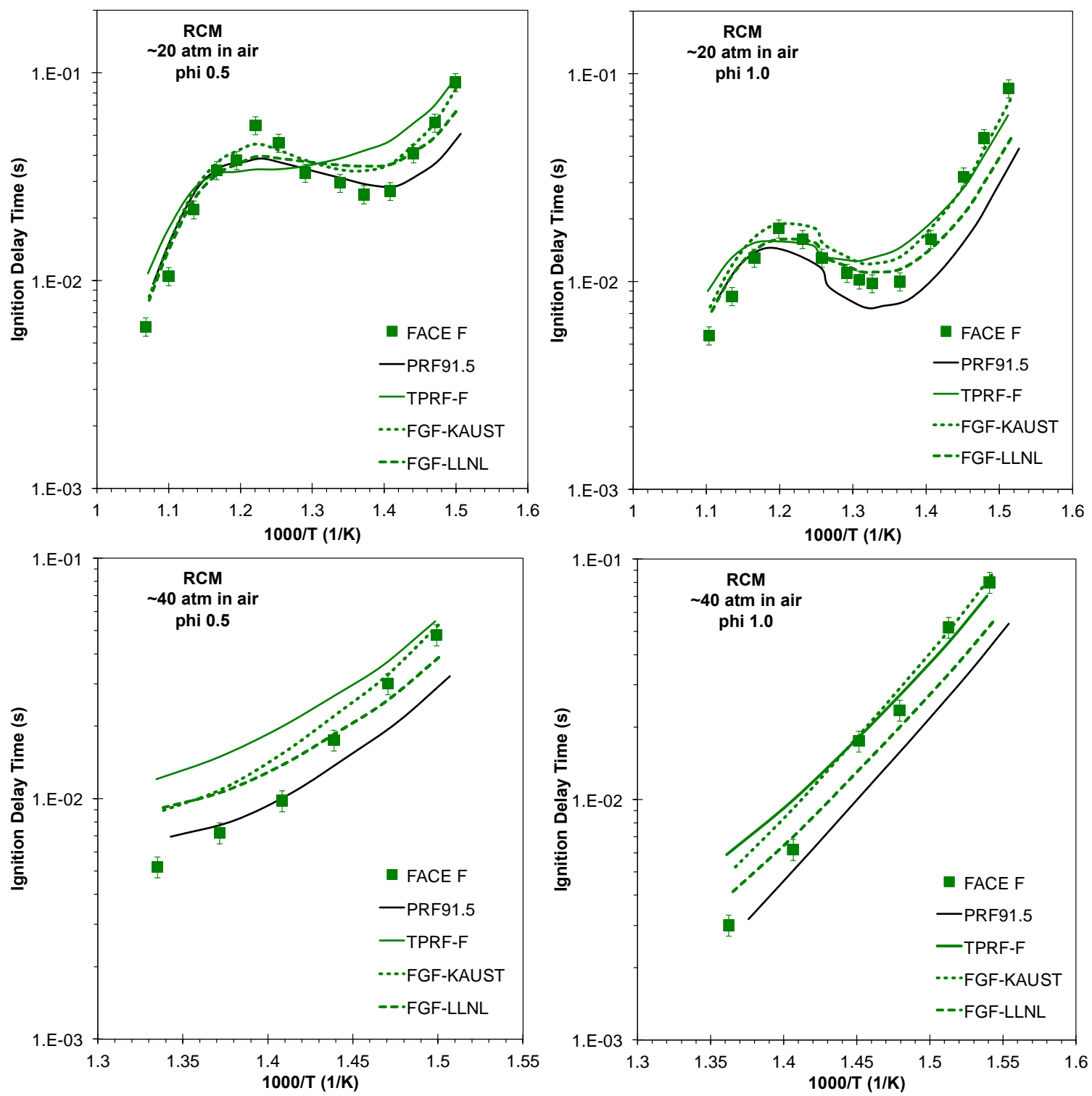

Figure 10. Simulated RCM ignition delays for various FACE F surrogate mixtures. Symbols are experimental RCM data and lines are variable volume simulations. Error bars represent the experimental uncertainty of $\pm 10 \%$.

Simulated FACE G ignition delay times under ST conditions are presented in Figure 11. The differences between FACE G surrogate simulations and experiments are much larger than those observed for FACE F, which highlights the challenge and complexity in predicting reactivity of highoctane sensitivity gasolines. For example, the PRF 91.5 surrogate does not yield the same activation energy (slope of ignition delay curve) as FACE G measurements at temperatures above $900 \mathrm{~K}$ (1000/T < 1.11). At temperatures below $900 \mathrm{~K}$, the PRF 91.5 surrogate displays prominent NTC behavior, 
which is not observed in the experiments. The lack of NTC in FACE G experiments is a characteristic of high octane sensitivity fuel [30,78], while the PRF 91.5 surrogate has zero octane sensitivity and shows significant NTC. The TPRF-G surrogate poorly reproduces the measured ignition delay times across the entire range of temperature, pressure, and equivalence ratios studied. At all conditions, the TPRF-G surrogate over-predicts the experimental data, which is attributed to the high concentration of toluene $(\sim 78.2 \mathrm{~mol} \%)$ that makes the mixture less reactive. Simulations performed using the LLNL and KAUST multicomponent surrogates accurately predict measured FACE G ignition delay times at temperatures above $900 \mathrm{~K}$ and all pressures and equivalence ratios. Below $900 \mathrm{~K}(1000 / T>1.11)$, the multicomponent surrogates are in qualitative agreement with the measurements, displaying similar NTC features at stoichiometric 20 and 40 atm conditions. At these lower temperatures, the FGGLLNL and FGG-KAUST surrogates over-predicts the FACE G measurements by at most a factor of two. 

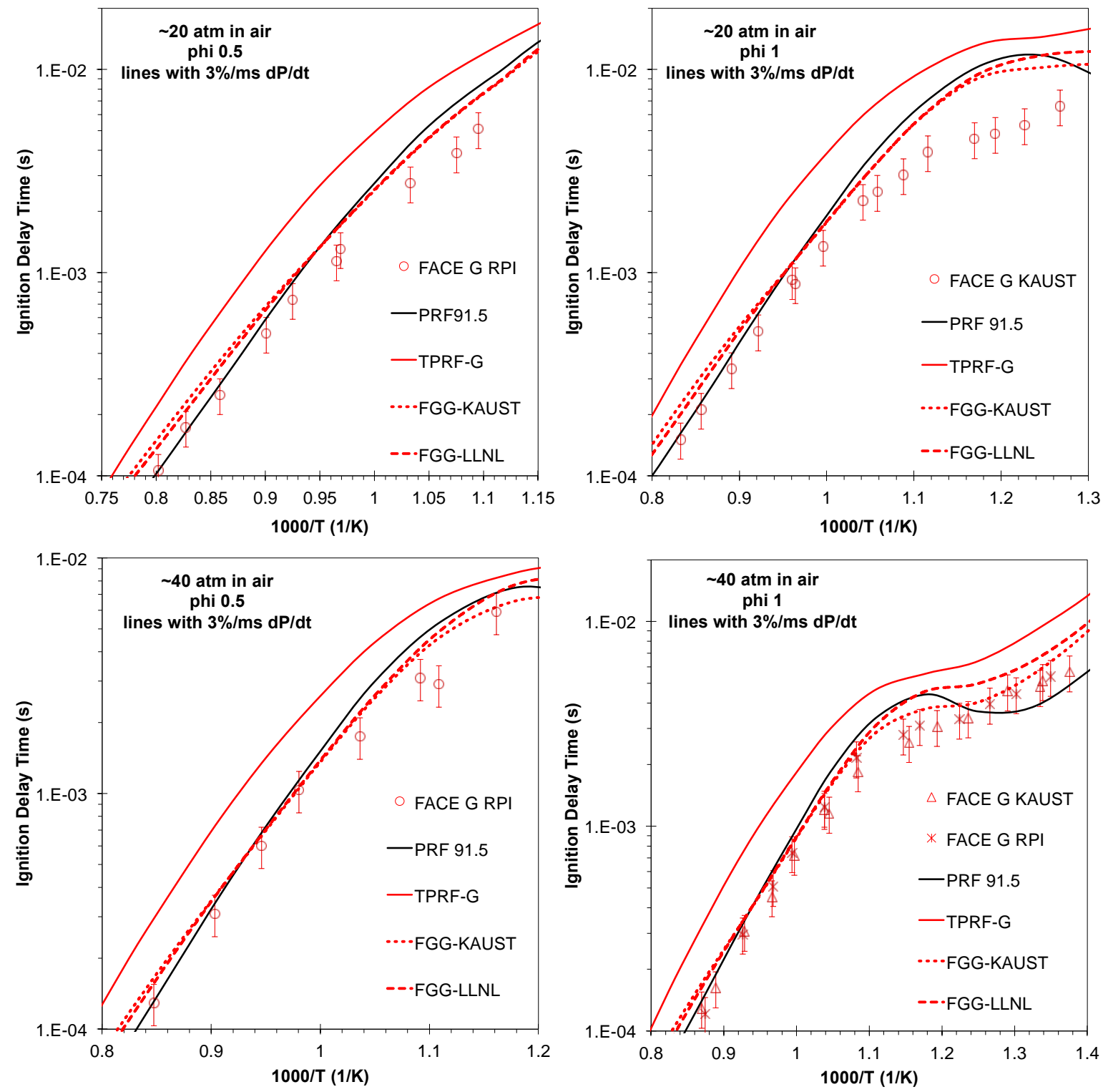

Figure 11. Simulated ST ignition delays for various FACE G surrogate mixtures. Symbols are experimental ST data and lines are simulations with $3 \%$ per $\mathrm{ms} \mathrm{dP} / \mathrm{dt}$. Error bars represent the experimental uncertainty of $\pm 20 \%$. Simulated ignition delays for FGG-KAUST and FGG-LLNL are indistinguishable at most conditions.

Simulated FACE G ignition delay times under RCM conditions are presented in Figure 12. As noted earlier for FACE F, the FACE G RCM data covers a broad temperature range from 650 to $940 \mathrm{~K}$ (1.06 $<1000 / T<1.54$ ) depending on the pressure and equivalence ratio being investigated. The PRF 91.5 surrogate does not qualitatively or quantitatively agree with the FACE G experimental measurements. At all pressure and equivalence ratio conditions below $900 \mathrm{~K}(1000 / T>1.11)$, the PRF 91.5 surrogate 
under-predicts the measured data. The TPRF-G surrogate over-predicts the FACE G experimental data at all conditions below $840 \mathrm{~K}$, again due to the high aromatic fraction in the surrogate. The multicomponent surrogates are in better agreement with the data than the PRF and TPRF surrogates, albeit some discrepancies still exist. Above 840 K $(1000 / T<1.19)$, the FGG-LLNL and FGG-KAUST surrogates agree with the FACE G data. The RCM data at $40 \mathrm{~atm}$ is restricted to temperatures below $750 \mathrm{~K}(1000 / T>1.33)$, and the FGG-KAUST surrogate predicts the data better than the FGG-LLNL surrogate. Similar observations were made at 20 atm low-temperature conditions. The NTC regime from 750 to $840 \mathrm{~K}(1.19<1000 / T<1.33)$ is where discrepancies exist between the surrogate modeling and the FACE gasoline experiments. Both multicomponent surrogates under-predict the data at 20 atm lean conditions, while there is better agreement at stoichiometric conditions. Similar to the case of FACE F, a discrepancy between ST and RCM data in the NTC regime must be considered when discussing the accuracy of the surrogate modeling. For 20 atm stoichiometric fuel/air mixtures in the temperature range of 800-900 K $(1.11<1000 / T<1.25)$, RCM measurements are up to a factor of three slower than ST data. The FGG-KAUST and FGG-LLNL surrogates generally predict ignition delay times in between those measured in the different experimental facilities. 

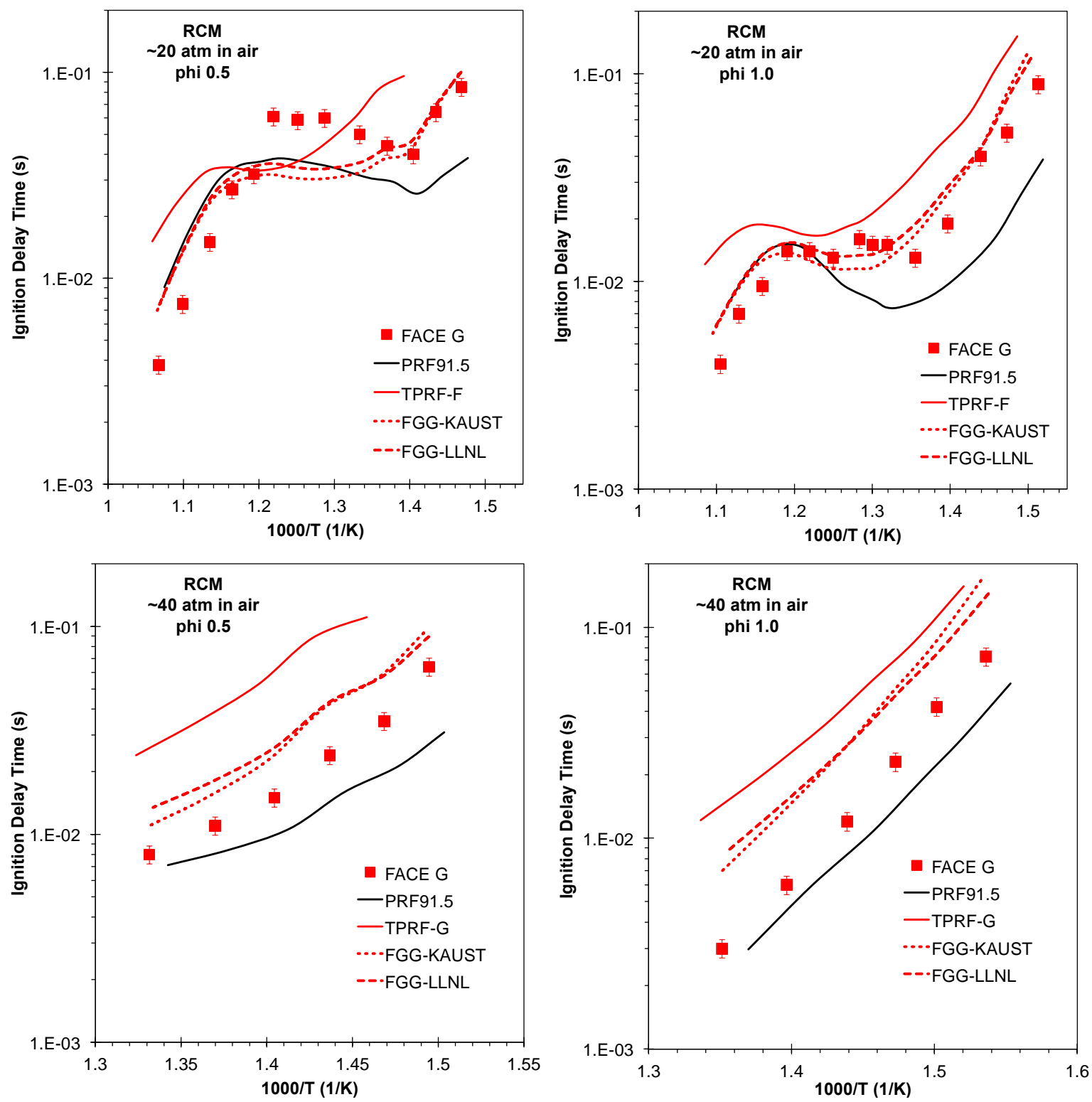

Figure 12. Simulated RCM ignition delays for various FACE G surrogate mixtures. Symbols are experimental RCM data and lines are variable volume simulations. Error bars represent the experimental uncertainty of $\pm 10 \%$. 


\subsection{Chemical kinetic modeling analysis and discussion}

The previous sections showed several interesting similarities and differences between the ignition characteristics of FACE F and G under various experimental conditions. The simulations with multicomponent surrogates were better than PRFs and TPRFs in reproducing the experimentally observed trends for both fuels over a wide range of conditions. This section presents simulations and kinetic analysis for the KAUST multicomponent surrogates (FGF-KAUST and FGG-KAUST), in order to provide insights into the effects of gasoline composition on ignition behavior. The KAUST multicomponent surrogates were selected for the present analysis because they capture the physical and chemical target properties of the FACE gasolines with high level of fidelity.

The upper row of Figure 13 presents ignition delay times for PRF 91.5, FGF-KAUST, and FGGKAUST obtained from constant volume (CV) adiabatic homogenous batch reactor simulations of stoichiometric fuel/air mixtures at 20 and $40 \mathrm{~atm}$. The results at both pressures indicate that higher RON fuels have longer ignition delay times at lower temperatures (e.g., below $760 \mathrm{~K}$ at 20 atm and 800 $\mathrm{K}$ at $40 \mathrm{~atm}$ ). PRF 91.5 (RON 91.5) is the most reactive followed by FGF-KAUST (RON 94.4) and then FGG-KAUST (RON 96.8). As the temperature increases and enters the NTC region, there is a notable crossover in reactivity with higher MON fuels being less reactive. Above $760 \mathrm{~K}$ at $20 \mathrm{~atm}$ and $800 \mathrm{~K}$ at $40 \mathrm{~atm}$, PRF 91.5 (MON 91.5) becomes the least reactive followed by FGF-KAUST (MON 88.8) and then FGG-KAUST (MON 85.8). These simulations are in qualitative agreement with the RCM experimental measurements, wherein higher RON fuels displayed longer ignition delay times in the low-temperature regime and higher MON fuels had longer ignition delay times in the NTC regime. The simulations also indicate that the magnitude of the negative slope in the NTC regime is largest for PRF $91.5(\mathrm{~S}=0)$, smaller for FGF-KAUST ( $\mathrm{S}=5.6$ ), and smallest for FGG-KAUST ( $\mathrm{S}=11$ ), which directly correlates to the octane sensitivity of the three fuels. These observations are consistent with those made by Leppard [78] and Mehl et al. [16,30] who showed that fuels with lower octane sensitivity are more "paraffin-like" and display pronounced NTC behavior.

To further study the effects of fuel composition on ignition characteristics, simulated temperature, $\mathrm{OH}$, and $\mathrm{HO}_{2}$ profiles for stoichiometric fuel/air mixture at 20 atm are shown in Fig. 13 for PRF 91.5 (middle row) and FGF-KAUST and FGG-KAUST (bottom row) for $700 \mathrm{~K}$ (left) and $825 \mathrm{~K}$ (right). These temperatures correspond to conditions at which ignition delay times roughly correlate with fuel RON and MON, respectively (see arrow markings in Figure 13). The mole fraction profiles of $\mathrm{OH}$ and 
$\mathrm{HO}_{2}$ are plotted on a semi-log scale to identify distinct regions of interest, following the analysis methods of Merchant et al. [81]. In their study on two-stage ignition of propane, Merchant and coworkers [81] identified two regions of global reactivity (i.e., first and second stages), wherein the first stage could be further subdivided into two distinct regions of exponential $\mathrm{OH}$ and $\mathrm{HO}_{2}$ radical growth. The accumulation of $\mathrm{OH}$ and $\mathrm{HO}_{2}$ radicals (stage-1a), the recombination of $\mathrm{HO}_{2}$ to form $\mathrm{H}_{2} \mathrm{O}_{2}$ (stage-1b, ends at first ignition stage), and eventual decomposition of $\mathrm{H}_{2} \mathrm{O}_{2}$ to $2 \mathrm{OH}$ radicals (overall ignition stage) [82] control the reactivity regimes.

In the present study, a clear two-stage ignition is observed for all the fuels at an initial temperature of $700 \mathrm{~K}$, which is in agreement with RCM measurements for FACE F and G in the LTR. The simulations (Figure 13) display reactivity regimes corresponding to the first ignition stage and overall ignition stage. During the first ignition stage, an exponential growth of $\mathrm{OH}$ and $\mathrm{HO}_{2}$ radicals culminates in a low temperature heat release event that raises the temperature of the system (see arrow markings in Figure 13). A short delay period is then observed, wherein $\mathrm{HO}_{2}$ radicals recombine to form $\mathrm{H}_{2} \mathrm{O}_{2}$ that eventually decomposes to cause the main ignition event [82].

At $700 \mathrm{~K}$, PRF 91.5 shows a slightly larger peak OH concentration in the first stage, which results in an earlier main-stage ignition compared to the FACE gasoline surrogates (see arrow markings in Figure 13). The multicomponent surrogates have higher RONs than PRF 91.5, so they display slower radical concentration growth rate, produce less $\mathrm{OH}$ during the first stage, and exhibit later overall ignition delay times. Won et al. [83] showed that fuels with larger peak $\mathrm{OH}$ concentration in the first stage ignition have shorter overall ignition delay times. They further demonstrated a linear relationship between fuel $\mathrm{CH}_{2} / \mathrm{CH}_{3}$ ratios and peak $\mathrm{OH}$ concentrations in the first stage; this finding was subsequently confirmed through experimental and kinetic modeling study on hexadecane isomers by Lapuerta et al. [84]. The higher peak $\mathrm{OH}$ concentration in the first stage for PRF 91.5 compared to FGF-KAUST and FGG-KAUST is expected due to the higher $n$ - and iso-paraffinic content in the PRF compared to the higher naphthenic, aromatic, and olefinic content in the multicomponent mixtures.

At $825 \mathrm{~K}$, the simulations for all fuels display a single-stage ignition behavior, which was also observed in the RCM measurements in the ITR. Within the NTC regime, PRF 91.5 is the least reactive due to its pronounced NTC characteristic, as indicated by the slower rate of radical buildup during the exponential growth phase. In the NTC regime, the lower MON (higher octane sensitivity) FACE 
gasoline surrogates populate the $\mathrm{OH}$ and $\mathrm{HO}_{2}$ radical pool quicker and display shorter main-stage ignition delay times.

At both $700 \mathrm{~K}$ and $825 \mathrm{~K}$, an interesting observation is that the primary difference between the three surrogate fuels (PRF 91.5, FGF-KAUST, and FGG-KAUST) is the rate of radical buildup during the exponential growth phase. The amount of radicals produced at the end of this growth phase is similar for the three fuels $\left(\mathrm{OH}\right.$ mole fraction of $\sim 10^{-7}-10^{-8}, \mathrm{HO}_{2}$ mole fraction of $\sim 10^{-4}-10^{-5}$ ), so this is not a distinguishing factor. Rather, a fuel that attains this critical concentration faster, for a given initial temperature and pressure condition, ignites sooner. Therefore, a rate of production analysis was conducted to see which reactions contribute to the production and consumption of important radicals during the exponential growth phase. Simulated rates of production of $\mathrm{H}, \mathrm{OH}$, and $\mathrm{HO}_{2}$ radicals are presented for PRF 91.5 (Figure 14) and FGF-KAUST and FGG-KAUST (Figure 15) at 20 atm and $700 \mathrm{~K}$ (RON-like) and $825 \mathrm{~K}$ (MON-like). The rates of production are presented at times corresponding to two-thirds of the maximum $\mathrm{OH}$ concentration (i.e., the first ignition stage denoted by an arrow in Fig. 13) in the exponential growth phase. The supplementary material contains a species dictionary to facilitate interpretation.

At lower RON-like temperatures (i.e., $700 \mathrm{~K}$ ), global reactivity is controlled by the relative importance of low-temperature chain branching, chain propagating, and chain terminating reactions that directly affect the concentration of $\mathrm{OH}$ radicals. The importance of these reaction pathways varies greatly with chemical functionality and carbon chain length. PRF 91.5 is largely comprised of $i s o$-octane; Figure 14 (left) shows that iso-octane is the primary consumer of $\mathrm{OH}$ radicals in PRF 91.5, while iso-octane's low-temperature chain propagation and branching reactions (cyclic ether formation and ketohydroperoxide decomposition) produce $\mathrm{OH}$ radicals. FGF-KAUST has a higher RON than PRF 91.5 and contains a notable amount of cyclopentane, as well as smaller amounts of 1,2,4-TMB and 1hexene. Figure 15 (left) shows that the $\mathrm{OH}$ radicals are consumed by 1-hexene, cyclopentane, and 1,2,4-TMB, while the oxidation of 1-hexene via the Waddington reaction $[41,85,86]$ produces $\mathrm{OH}$ radicals. FGG-KAUST has the highest RON and a larger fraction of aromatics (1,2,4-TMB and toluene), in addition to cyclopentane and 1-hexene. Figure 15 shows that 1,2,4-TMB, cyclopentane, and 1-hexene in FGG-KAUST consume $\mathrm{OH}$ radicals, while $\mathrm{OH}$ radicals are produced by 1-hexene Waddington reactions. In summary, PRF 91.5 is the most reactive at $700 \mathrm{~K}$ because its high paraffinic content leads to fast low-temperature chain carrying reactions, while the multicomponent surrogates 
display lower reactivity due to slower kinetics related to the low-temperature oxidation of cyclopentane, 1,2,4-trimethylbenzene, and 1-hexene.

At $825 \mathrm{~K}$, the fuel/air mixtures are in the NTC regime and do not display two-stage ignition characteristics. Under these conditions, the global reactivity is controlled by the buildup of $\mathrm{OH}$ radicals and the eventual decomposition of $\mathrm{H}_{2} \mathrm{O}_{2}$ to two $\mathrm{OH}$ radicals at the main ignition event [82]. $\mathrm{H}_{2} \mathrm{O}_{2}$ is primarily produced when $\mathrm{HO}_{2}$ radicals abstract $\mathrm{H}$-atoms from hydrocarbon fuel molecules; therefore, $\mathrm{HO}_{2}$ radical formation pathways are also important in controlling global reactivity. Again, PRF 91.5 in Figure 14 (right) shows that $i$ so-octane and $n$-heptane are the primary consumers of $\mathrm{OH}$ radicals, while $\mathrm{OH}$ radicals are produced via cyclic ether formation, a chain propagating pathway. The lower MON FGF-KAUST is slightly more reactive than PRF 91.5 under these conditions. The FGFKAUST rates of production in Figure 15 (right) show that $\mathrm{OH}$ and $\mathrm{HO}_{2}$ radical concentrations are controlled by reactions related to cyclopentane, 1,2,4-TMB, 1-hexene, and iso-octane. The higher aromatic FGG-KAUST shown in Figure 15 (right) shows a greater amount of $\mathrm{OH}$ produced via decomposition of trimethylbenzyl hydroperoxy radicals that are produced from the reaction of $\mathrm{HO}_{2}$ with trimethylbenzyl radicals [54,87-89]. FGG-KAUST also shows increased $\mathrm{HO}_{2}$ radical production from concerted elimination [90] of cyclopentane and from the $\mathrm{H}+\mathrm{O}_{2} \Leftrightarrow \mathrm{HO}_{2}$ reaction. $\mathrm{H}$ radicals are produced in large quantities in FGG-KAUST via decomposition of benzoxyl radicals [91], as shown in the upper right panel of Figure 15. A previous study by Vanhove et al. [89] showed that mixtures containing aromatics are more reactive at higher temperatures due to the ability of $\mathrm{HO}_{2}$ radicals to abstract labile benzylic radicals thereby forming $\mathrm{H}_{2} \mathrm{O}_{2}$. They also showed that $\mathrm{HO}_{2}$ radical can react with benzylic radicals to form $\mathrm{OH}$ and benzoxyl radicals, as seen in this study for FACE gasoline mixtures containing 1,2,4-TMB. Thus, the presence of both cyclopentane and 1,2,4-TMB in FACE G creates a synergy that increases reactivity in the NTC region. Our findings are contrary to previous work [92] suggesting that cycloalkane functionality does not impart any significant effect on the low temperature oxidation of complex fuels.

The rate of production analyses is supplemented by sensitivity analyses to determine which reactions control system reactivity, as shown in Figure 16 for FGF-KAUST (left) and FGG-KAUST (right). The analysis is performed under constant volume adiabatic simulations at 20 atm and temperatures of $700 \mathrm{~K}$ (top) and $825 \mathrm{~K}$ (bottom). The relative sensitivity (Srel) is defined as Srel $=\ln \left(s_{2} / s_{1}\right) / \ln \left(k_{2} / k_{1}\right)$, where $s_{1}$ is the original total ignition delay time corresponding to the unperturbed reaction rate constant $k_{1}$, 
and $s_{2}$ is the total ignition delay time corresponding to a doubling of the forward and reverse rate constants (i.e., $k_{2}=2 k_{1}$ ). This definition results in negative sensitivity coefficients for reactions that decrease ignition delay times. The results presented here are consistent with those presented earlier for RD387 surrogates [17] and FACE A and C surrogates [12], wherein reactivity was shown to be controlled by important small molecules and reactions related to the primary fuel components. At both $700 \mathrm{~K}$ and $825 \mathrm{~K}$, FGF-KAUST and FGG-KAUST are sensitive to isomerization of cyclopentylperoxy $\left(\mathrm{RO}_{2}\right)$ radicals to $\mathrm{QOOH}$ and concerted elimination of cyclopentylperoxy, which together determine the ratio of low-temperature chain branching to termination. In FGF-KAUST, there is a considerable fraction of iso-octane; abstractions from its "A" and "B" sites increase reactivity as this path leads to branching, while abstraction from its " $\mathrm{C}$ " site decreases reactivity since it leads to termination. FGGKAUST has less iso-octane and more 1,2,4-TMB, so at $700 \mathrm{~K}$ abstraction from 1,2,4-TMB decreases reactivity. At $825 \mathrm{~K}$, the reaction of benzylic radicals with $\mathrm{HO}_{2}$ is important, and increasing this rate will increase reactivity as it leads to $\mathrm{OH}$ radical production. 

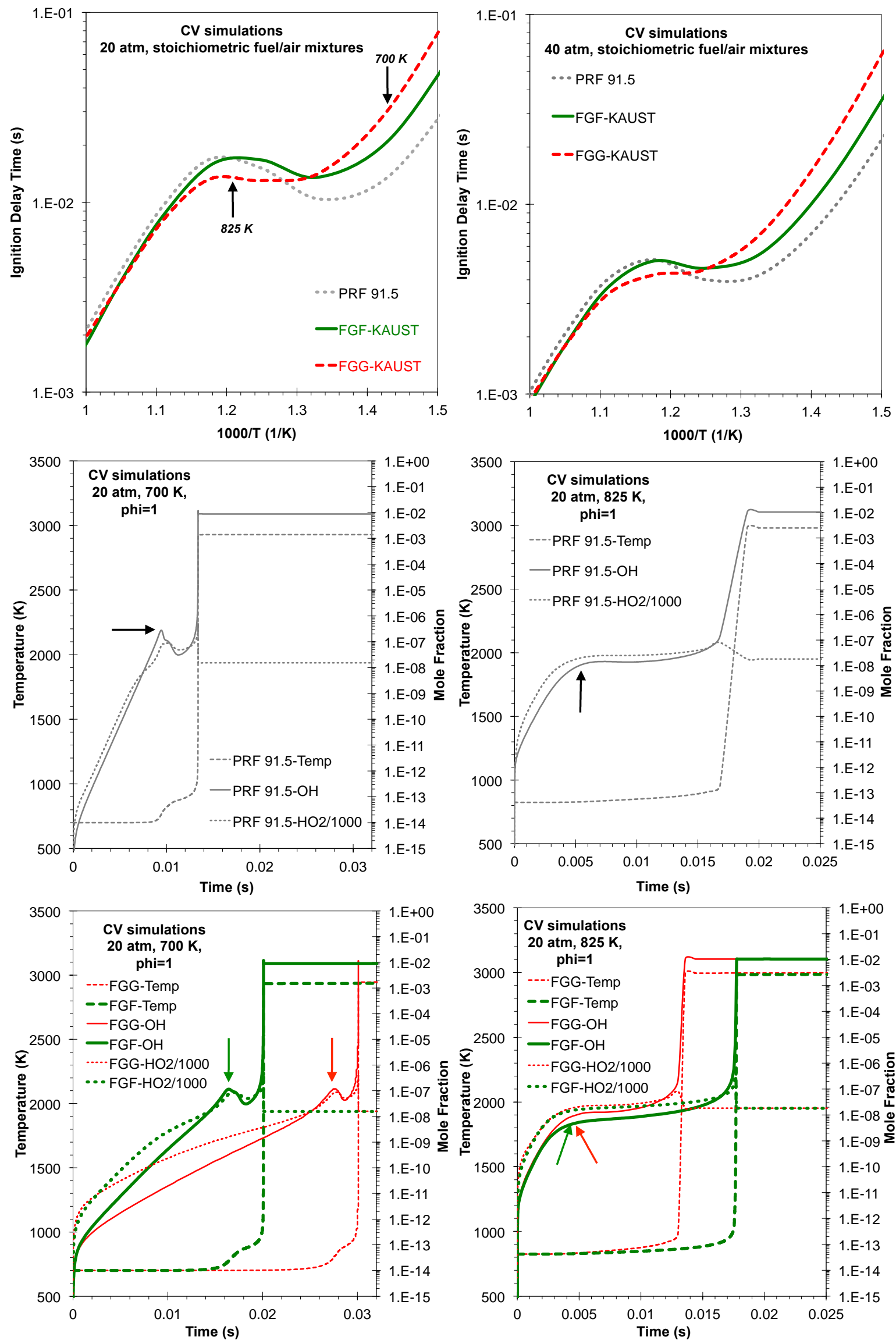
1

2

Figure 13. Simulated constant volume ignition delay times for PRF 91.5, FGF-KAUST, and FGGKAUST stoichiometric mixtures with air at 20 atm (top left) and 40 atm (top right). Middle and bottom panels depict simulated temperature and $\mathrm{OH}$ time-histories for stoichiometric fuel/air mixtures at $20 \mathrm{~atm} 700 \mathrm{~K}$ (left) and $825 \mathrm{~K}$ (right). Arrows mark points of interest (see text). 

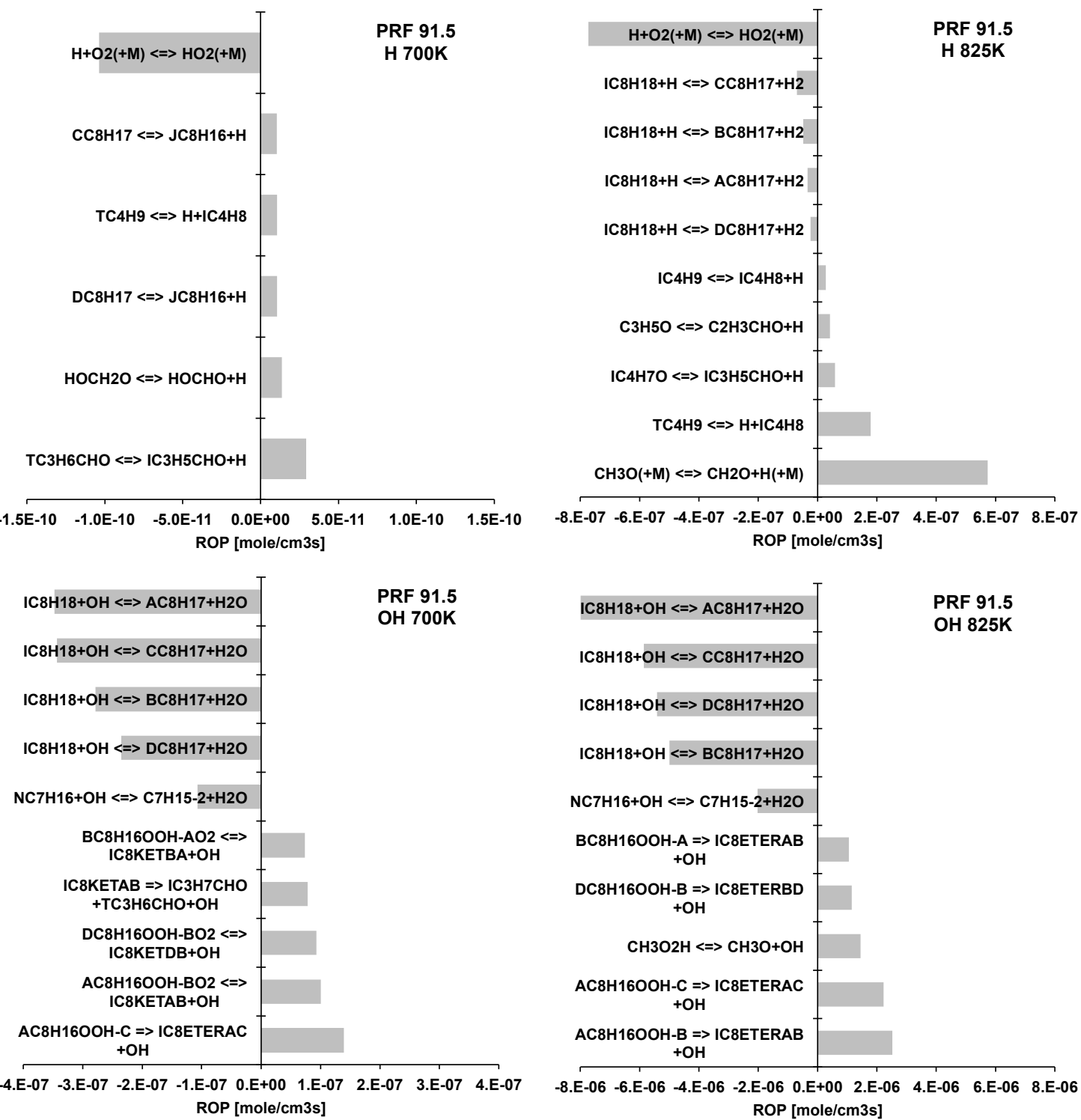

IC8H18+OH $\Leftrightarrow \mathrm{CC} 8 \mathrm{H} 17+\mathrm{H} 2 \mathrm{O}$

IC8H18+OH $\Leftrightarrow$ DC8H17+H2O

IC8H18+OH $\Leftrightarrow$ BC8H17+H2O

$\mathrm{NC} 7 \mathrm{H} 16+\mathrm{OH} \Leftrightarrow=>\mathrm{C} 7 \mathrm{H} 15-2+\mathrm{H} 2 \mathrm{O}$

BC8H16OOH-A $=>$ IC8ETERAB $+\mathrm{OH}$

DC8H16OOH-B $=>$ IC8ETERBD $+\mathrm{OH}$

$\mathrm{CH} 3 \mathrm{O} 2 \mathrm{H} \Leftrightarrow=\mathrm{CH} 3 \mathrm{O}+\mathrm{OH}$

AC8H160OH-C $=>$ IC8ETERAC $+\mathrm{OH}$

AC8H16OOH-B $=>$ IC8ETERAB $+\mathrm{OH}$

-8.E-06 -6.E-06 -4.E-06 -2.E-06 0.E+00 2.E-06 4.E-06 6.E-06 8.E-06 ROP [mole/cm3s]

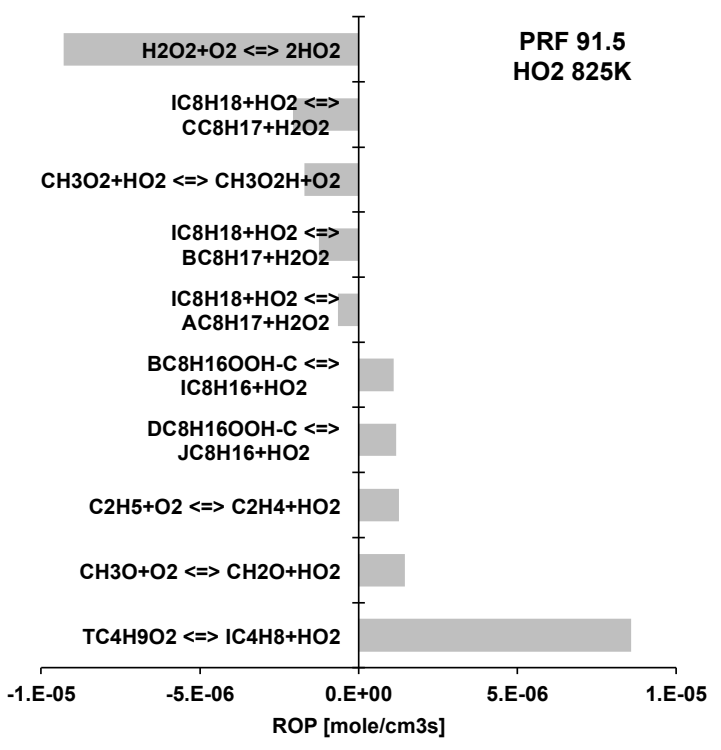


1

2

3

7

8
Figure 14 . Rate of production of $\mathrm{H}$ (top), $\mathrm{OH}$ (middle), and $\mathrm{HO}_{2}$ (bottom) radicals for PRF 91.5 at 20 atm and $700 \mathrm{~K}$ (left) and $825 \mathrm{~K}$ (right). The rate of production is given for the time corresponding to two-thirds of the maximum $\mathrm{OH}$ concentration in the exponential growth phase. 

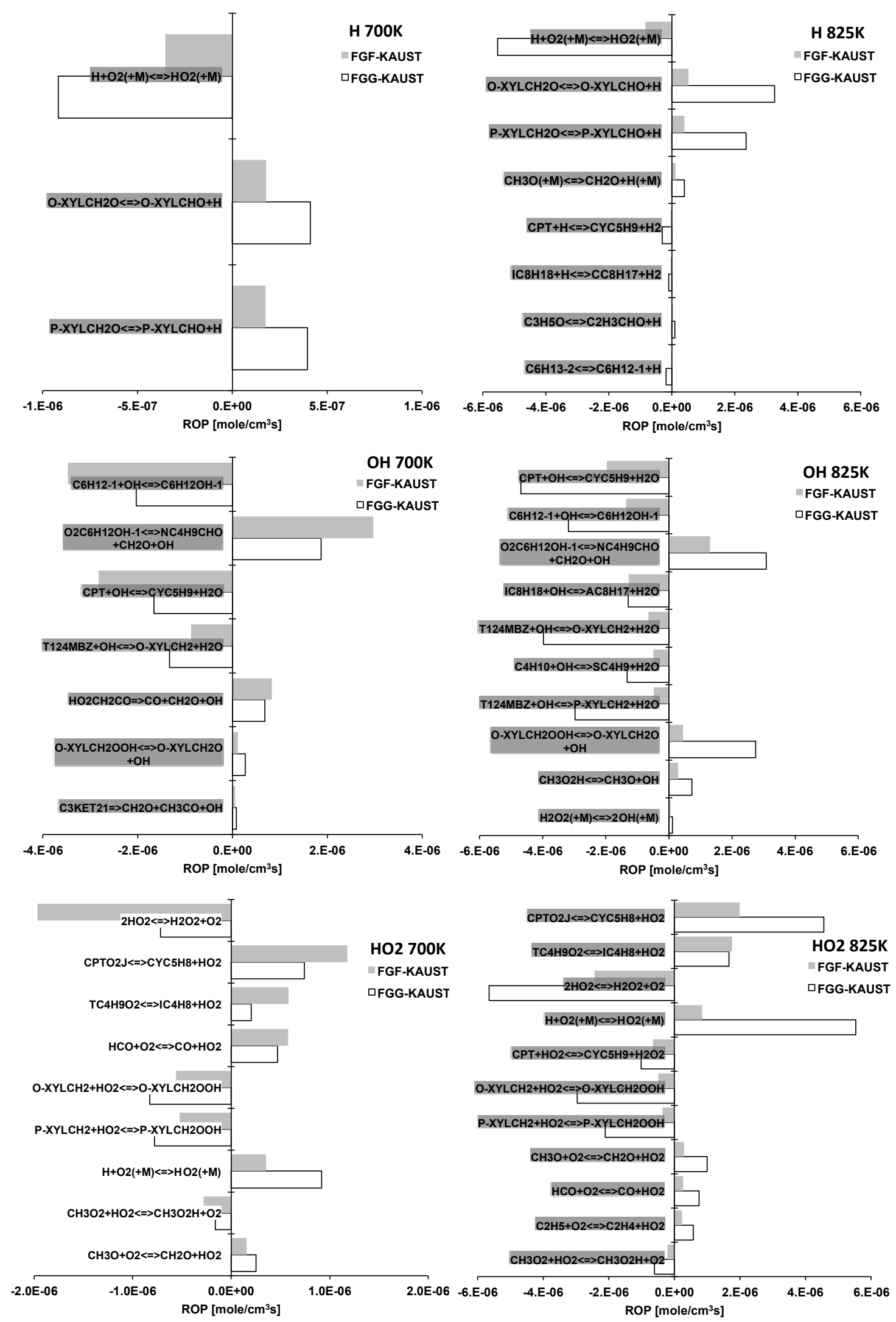
Figure 15. Rate of production of $\mathrm{H}$ (top), $\mathrm{OH}$ (middle), and $\mathrm{HO}_{2}$ (bottom) radicals for FACE $\mathrm{F}$ and $\mathrm{G}$ at $20 \mathrm{~atm}$ and $700 \mathrm{~K}$ (left) and $825 \mathrm{~K}$ (right). The rate of production is given for the time corresponding to two-thirds of the maximum $\mathrm{OH}$ concentration in the exponential growth phase.
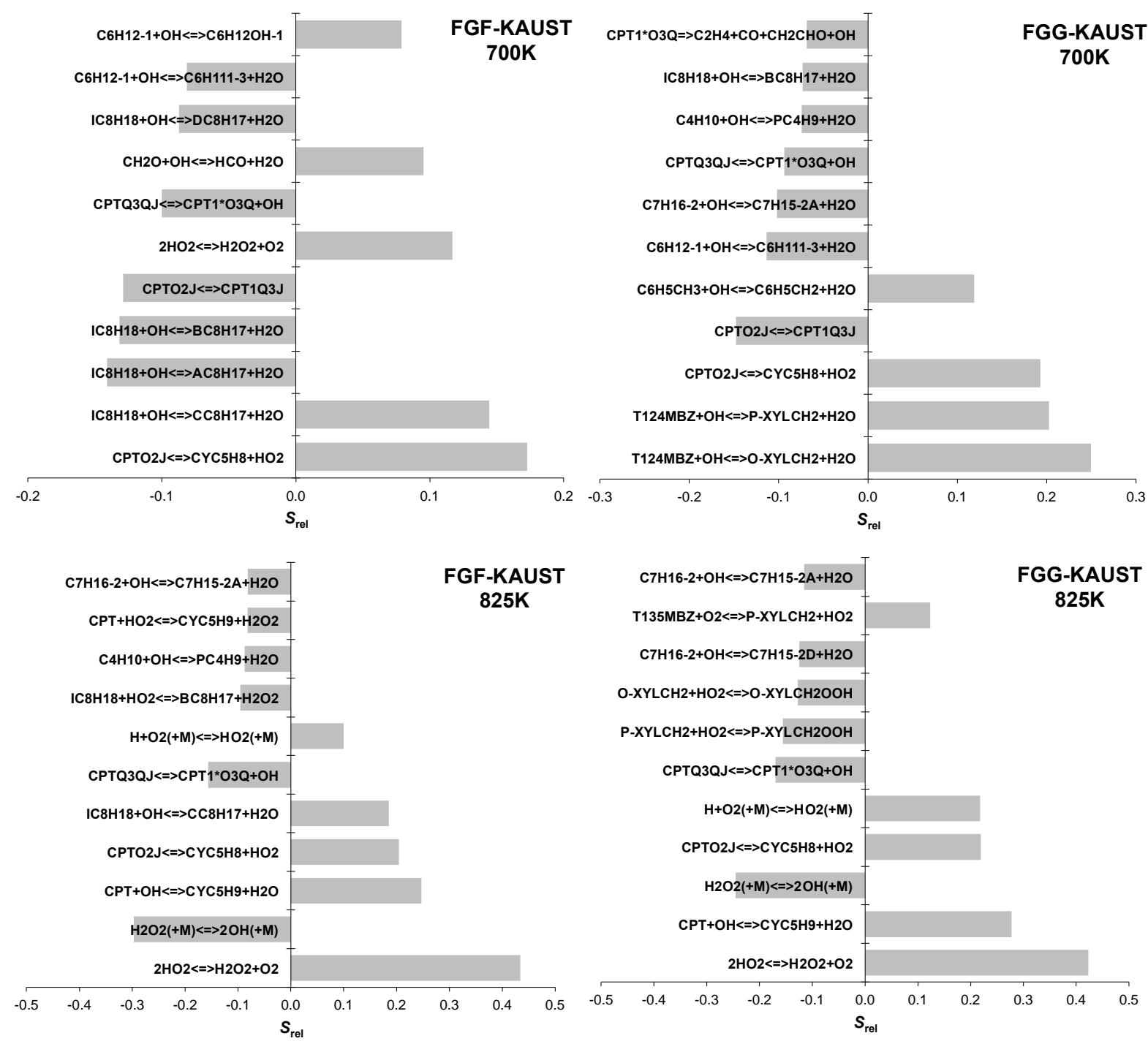

Figure 16. Sensitivity of total ignition delay time to changes in reaction rate coefficients for FGFKAUST (left) and FGG-KAUST (right). Simulation results are for constant volume adiabatic stoichiometric fuel/air mixtures at 20 atm and $700 \mathrm{~K}$ (top) and $825 \mathrm{~K}$ (bottom). 


\section{Summary and conclusions}

In this work, the effects of gasoline fuel composition on ignition behavior were studied using experimental measurements and chemical kinetic modeling of surrogate fuel mixtures. Shock tubes and a rapid compression machine were utilized to obtain ignition delay time measurements for two FACE gasolines ( $F$ and $\mathrm{G}$ ) with similar AKI but varying octane sensitivity and composition. Detailed chemical and physical characterizations of the test fuels were conducted to identify target properties for surrogate fuel formulation. Chemical kinetic simulations for various surrogate fuel mixtures were utilized to understand the experimentally observed differences between the FACE gasolines.

The experimental results indicated that the two FACE gasolines display similar reactivity at high temperatures (above $900 \mathrm{~K}$ ) for any given pressure and equivalence ratio condition, regardless of their octane rating (i.e., $\mathrm{F}$ and $\mathrm{G}$ at $\mathrm{AKI} 91.5$ are similar to FACE $\mathrm{A}$ and $\mathrm{C}$ at $\mathrm{AKI} 84$ ). However, experiments below $900 \mathrm{~K}$ in the NTC and low-temperature regimes showed that ignition delay times decreased with increasing AKI (i.e., FACE $F$ and $G$ were less reactive than FACE A and C). Furthermore, FACE G, which has a higher RON than FACE F, was less reactive at low temperatures, while FACE F with its lower octane sensitivity displayed more NTC behavior than FACE G. The RCM measurements demonstrated that for compressed temperatures between 800 and 900 K, FACE G is more reactive than FACE F, which is consistent with the lower MON of the former. The effect of fuel octane sensitivity was further depicted in RCM two-stage ignition pressure profiles, wherein the lower octane sensitivity FACE F displayed greater first-stage pressure rise (i.e., more LTHR) than the higher octane sensitivity FACE G. At conditions showing single stage ignition, the higher octane sensitivity FACE G displays more ITHR than the lower octane sensitivity FACE F. These results suggest that LTHR increases and ITHR decreases with decreasing octane sensitivity. These relationships between fuel octane sensitivity and heat release (LTHR and ITHR) have important ramifications of combustion phasing, fuel stratification, and operability limits of low-temperature combustion engines [80,93-99].

Surrogate fuels were formulated in order to conduct chemical kinetic modeling for FACE F and G ignition. Various surrogate fuel formulation methodologies were employed to determine which ones are most suitable for reproducing specific target properties and experimentally observed ignition behavior. PRF, TPRF, and multicomponent surrogates were formulated for each FACE gasoline and 
compared against chemical target properties (i.e., RON, MON, PIONA, H/C ratio, and carbon types) and physical target properties (density, average molecular weight, and distillation curve). The multicomponent surrogates based on methods developed at LLNL and KAUST, respectively, were able to adequately reproduce a wide range of FACE F and G target properties. KLSA measurements in a CFR engine for FACE F and G and their corresponding multicomponent surrogates demonstrated the suitability of the surrogate formulation approach. Ignition delay simulations were then conducted using the various surrogate mixtures. The FACE F ignition characteristics were adequately reproduced by all of the surrogates (e.g., PRF 91.5, TPRF-F, FGF-LLNL, FGF-KAUST). However, ignition characteristics of FACE G were only qualitatively and quantitatively captured by the multicomponent surrogates (FGG-LLNL and FGF-KAUST). TPRF mixtures for high octane sensitivity gasolines have been shown to match the engine performance characteristics in SI engines [21], but such surrogates were not suitable for simulating ignition delay under ST and RCM conditions studied herein. The present and previous [12] results suggest that the ignition behaviors of lower octane sensitivity gasolines (e.g., FACE F, S=5.6; FACE A and C, S=0) can be modeled as simple binary PRF or ternary PRF mixtures. However, the ignition behavior of high octane sensitivity gasolines (e.g., FACE G, $\mathrm{S}=11$ ) require more complex multicomponent surrogate mixtures.

Chemical kinetic analyses were also performed using the KAUST surrogates to provide deeper insights into the effects of fuel composition on the ignition behavior of FACE F and G compared to PRFs. Simulations of stoichiometric fuel/air mixtures at 20 atm qualitatively reproduced the experimentally observed trends, wherein mixtures with higher RON were less reactive at $700 \mathrm{~K}$ while those with higher MON were less reactive at $825 \mathrm{~K}$. The simulations displayed a less pronounced NTC behavior for mixtures with higher octane sensitivity. The rates of production of $\mathrm{OH}$ and $\mathrm{HO}_{2}$ radicals were compared for different surrogate mixtures to demonstrate the relationship between fuel composition and ignition quality. The higher reactivity of the low RON PRF at $700 \mathrm{~K}$ was linked to the predominance of iso-octane low-temperature chain branching reactions, while the aromatic, naphthenic, and olefinic fractions in the higher RON FACE gasoline surrogates suppressed lowtemperature reactivity. At $825 \mathrm{~K}$, the increased aromatic fraction in FACE surrogates increases reactivity due to greater $\mathrm{OH}$ radical production from reaction of benzylic radicals with $\mathrm{HO}_{2}$. It was shown that the FACE G surrogate is the most reactive in the NTC region due to significant amounts of both cyclopentane and 1,2,4-trimethylbenzene, which accelerate the rate of $\mathrm{H}, \mathrm{OH}$, and $\mathrm{HO}_{2}$ radicals. This is because cyclopentyl radicals undergo concerted elimination to produce $\mathrm{HO}_{2}$ radicals that 
subsequently react with trimethylbenzyl radicals to form $\mathrm{OH}$ radicals. This synergy in reaction kinetics demonstrates the need for complex multicomponent surrogates to reproduce the observed ignition characteristics of gasoline fuels. Furthermore, a deeper understanding on the effects of chemical cross linking in determining the antiknock quality of complex mixtures can help design fuels for nextgeneration engine technologies.

\section{Acknowledgements}

The authors are grateful to Hendrik Muller (Saudi Aramco R\&DC), Jihad Badra (Saudi Aramco R\&DC), Abdulla Algam (Saudi Aramco R\&DC), Emad Alawi (Saudi Aramco R\&DC), and Nadim Hourani (KAUST) for the DHA results. The KAUST authors acknowledge funding support from the Clean Combustion Research Center and from Saudi Aramco under the FUELCOM program. The work at the University of Connecticut was supported by the National Science Foundation under Grant No. CBET-1402231. The Rensselaer group was supported by the U.S. Air Force Office of Scientific Research (Grant No. FA9550-11-1-0261) with Dr. Chiping Li as technical monitor. The LLNL work was performed under the auspices of the US Department of Energy by Lawrence Livermore National Laboratory under Contract DE- AC52-07NA27344 and was supported by the U.S. Department of Energy, Office of Vehicle Technologies, Gurpreet Singh, program manager.

\section{References}

1. A. Amer, H. babiker, J. Chang, G. Kalghatgi, P. Adomeit, A. Brassat, M. Günther, Fuel effects on knock in a highly boosted direct injection spark ignition engine, SAE 2012-011634 (2012) 1-18.

2. V. Mittal, J.B. Heywood, The shift in relevance of fuel RON and MON to knock onset in modern SI engines over the last 70 years, SAE 2009-11-02 (2009) 1-10.

3. R. Cracknell, W. Warnecke, J.H. Redmann, T.K. Goh, Octane requirements of modern downsized boosted gasoline engines, MTZ Worldwide 76 (2015), 4-7.

4. ASTM D2699-12, Standard Test Method for Research Octane Number of Spark-Ignition Engine Fuel, ASTM International, West Conshohocken, PA, 2012

5. ASTM D2700-16, Standard Test Method for Motor Octane Number of Spark-Ignition Engine Fuel, ASTM International, West Conshohocken, PA, 2016

6. G.T. Kalghatgi, Developments in internal combustion engines and implications for combustion science and future transport fuels, Proc. Combust. Inst. 35 (2015) 101-115. 
7. G.T. Kalghatgi, The outlook for fuels for internal combustion engines, Int. J. Engines, 15 (2014) 383-398.

8. G.T. Kalghatgi, Fuel/Engine Interactions. SAE international, Warrendale PA (2014).

9. G.T. Kalghatgi, Fuel anti-knock quality - Part I. Engine studies, SAE 2001-01-3584 (2011) $1-14$.

10. G.T. Kalghatgi, Fuel anti-knock quality - Part II. Vehicle studies - How relevant is motor octane number (MON) in modern engines, SAE 2001-01-3585 (2011) 1-13.

11. B.M. Gauthier, D.F. Davidson, R.K. Hanson, Shock tube determination of ignition delay times in full blend and surrogate fuel mixtures, Combust. Flame 139 (2004) 300-311.

12. S.M. Sarathy, G. Kukkadapu, M. Mehl, W. Wang, M. Mehl, W. Wang, T. Javed, S. Park, M.A. Oehlschlaeger, A. Farooq, W.J. Pitz, C.-J. Sung, Ignition of alkane rich FACE gasoline fuels, Proc. Combust. Inst., 35 (2015) 249-257.

13. G. Kukkadapu, K. Kumar, C.-J. Sung, M. Mehl, W.J. Pitz, Autoignition of gasoline and its surrogates in a rapid compression machine, Proc. Combust Inst., 34 (2013) 345-352.

14. G. Kukkadapu, K. Kumar, C.-J. Sung, M. Mehl, W.J. Pitz, Experimental and surrogate modeling study of gasoline ignition in a rapid compression machine, Combust. Flame, 159 (2012) 3066-3078.

15. W.J. Pitz, N. Cernansky, F.L. Dryer, F. Egolfopoulos, J.T. Farrell, D. Friend, H. Pitsch, Development of an experimental database and chemical kinetic models for surrogate gasoline fuels, SAE 2007-01-175 (2007).

16. M. Mehl, J.-Y. Chen, W.J. Pitz, S.M. Sarathy, C.K. Westbrook, An approach for formulating surrogates for gasoline with application towards a reduced surrogate mechanism for CFD engine modeling, Energy Fuels, 25 (2011) 5215-5223.

17. G. Kukkadapu, K. Kumar, C.-J. Sung, M. Mehl, W.J. Pitz, Autoignition of gasoline surrogates at low temperature combustion conditions, Combust. Flame, 162 (2015) 1-14.

18. C.V. Naik, K. Puduppakkam, C. Wang, J. Kottalam, L. Liang, D. Hodgson, E. Meeks, Applying detailed kinetics to realistic engine simulation: The surrogate blend optimizer and mechanism reduction strategies, SAE 2010-01-0541 (2010) 1-19.

19. K. Puduppakkam, L. Liang, C. Naik, E. Meeks, B.G. Bunting, Combustion and emissions modeling of gasoline HCCI engine using model fuels, SAE Technical Paper, 2009-01-0669 (2009) 1-11. 
20. A. Ahmed, G. Goteng, V.S.B. Shankar, K. Al-Qurashi, W.L. Roberts, S.M. Sarathy, A computational methodology for formulating gasoline surrogate fuels with accurate physical and chemical kinetic properties, Fuel 143 (2015) 290-300.

21. G. Kalghatgi, H. Babiker, J. Badra, A simple method to predict knock using toluene , nheptane, and iso- octane blends (TPRF) as gasoline surrogates, SAE Int. J. Engines, SAE 2015-1-757 (2015) 1-14.

22. J.C.G. Andrae, P. Björnbom, R.F. Cracknell, G.T. Kalghatgi, Autoignition of toluene reference fuels at high pressures modeled with detailed chemical kinetics, Combust. Flame, 149 (2007) 2-24.

23. J.C.G. Andrae, Development of a detailed kinetic model for gasoline surrogate fuels, Fuel, 87 (2008) 2013-2022.

24. J.C.G. Andrae, Comprehensive chemical kinetic modeling of toluene reference fuels oxidation, Fuel, 107 (2013) 740-748.

25. C. Pera, V. Knop, Methodology to define gasoline surrogates dedicated to auto-ignition in engines, Fuel, 96 (2012) 59-69.

26. N. Morgan, A. Smallbone, A. Bhave, M. Kraft, R. Cracknell, G. Kalghatgi, Mapping surrogate gasoline compositions into RON/MON space, Combust. Flame, 157 (2010) 11221131.

27. O.S. Abianeh, M.A. Oehlschlaeger, C.-J. Sung, A surrogate mixture and kinetic mechanism for emulating the evaporation and autoignition characteristics of gasoline fuel, Combust. Flame, 162 (2015) 3373-3784.

28. D. Bradley, C. Morley, M.J. Pilling, Low Temperature Combustion and Auto-Ignition, Chem. Kinet. 35 (1997) 661-760.

29. D. Bradley, C. Morley, H.L. Walmsley, Relevance of Research and Motor Octane Numbers to the Prediction of Engine Autoignition, SAE 2004-01-1970 (2004) 1-15.

30. M. Mehl, T. Faravelli, F. Giavazzi, E. Ranzi, P. Scorletti, A. Tardani, D. Terna, Detailed Chemistry Promotes Understanding of Octane Numbers and Gasoline Sensitivity, Energy Fuel, 20 (2006) 2391-2398.

31. J.A. Badra, N. Bokhumseen, N. Mulla, S.M. Sarathy, A. Farooq, G. Kalghatgi, P. Gaillard, A methodology to relate octane numbers of binary and ternary n-heptane, iso-octane and toluene mixtures with simulated ignition delay times, Fuel 160 (2015) 458-469. 
32. J.C.G. Andrae, R.A. Head, HCCI experiments with gasoline surrogate fuels modeled by a semidetailed chemical kinetic model, Combust. Flame 156 (2009) 842-851.

33. R.F. Cracknell, J.C.G. Andrae, L.J. McAllister, M. Norton, H.L. Walmsley, Performance and exhaust emission characteristics of a CI engine fueled with diesel-nitrogenated additives, Combust. Flame 156 (2009) 1046-1052.

34. W. Cannella, M. Foster, G. Gunter, W.R. Leppard, FACE gasolines and blends with ethanol: detailed characterization of physical and chemical properties, CRC Report No. AVFL-24 (2014) 1-60.

35. W. Wang, S. Gowdagiri, M.A. Oehlschlaeger, The high-temperature autoignition of biodiesels and biodiesel components, Combust. Flame, 161 (2014) 3014-3021.

36. H.-P.S. Shen, J. Steinberg, J. Vanderover, M.A. Oehlschlaeger, A shock tube study of the ignition of n-heptane, n-decane, n-dodecane, and n-tetradecane at elevated pressures, Energy Fuels, 23 (2009) 2482-2489.

37. S.M. Burke, U. Burke, R. Mc Donagh, O. Mathieu, I. Osorio, C. Keesee, A. Morones, E.L. Petersen, W. Wang, T.A. DeVerter, M.A. Oehlschlaeger, B. Rhodes, R.K. Hanson, D.F. Davidson, B.W. Weber, C.-J. Sung, J. Santner, Y. Ju, F.M. Haas, F.L. Dryer, E.N. Volkov, E.J.K. Nilsson, A.A. Konnov, M. Alrefae, F. Khaled, A. Farooq, P. Dirrenberger, P.-A. Glaude, F. Battin-Leclerc, H.J. Curran, An experimental and modeling study of propene oxidation. Part 2: Ignition delay time and flame speed measurements, Combust. Flame 162 (2015) 296-314.

38. A.K. Das, C.-J. Sung, Y. Zhang, G. Mittal, Ignition delay study of moist hydrogen/oxidizer mixtures using a rapid compression machine, Int. J. Hydrogen Energy, 37 (2012) 6901 6911.

39. G. Mittal, C.-J. Sung, A rapid compression machine for chemical kinetics studies at elevated pressures and temperatures, Combust. Sci. Technol. 179 (2007) 497-530.

40. Nadkarni R., Guide to ASTM test methods for the analysis of petroleum products and lubricants. ASTM International (2007).

41. M. Mehl, G. Vanhove, W.J. Pitz, E. Ranzi, Oxidation and combustion of the n-hexene isomers: A wide range kinetic modeling study, Combust. Flame, 155 (2008) 756-772. 
42. M. Mehl, W.J. Pitz, C.K. Westbrook, H.J. Curran, Kinetic modeling of gasoline surrogate components and mixtures under engine conditions, Proc. Combust. Inst., 33 (2011) 193200.

43. W.K. Metcalfe, S.M. Burke, S.S. Ahmed, H.J. Curran, A hierarchical and comparative kinetic modeling study of C1 - C2 hydrocarbon and oxygenated fuels, Int. J. Chem. Kinet., 45 (2013) 638-675.

44. D. Healy, D. Kalitan, C. Aul, E. Petersen, G. Bourque, H.J. Curran, Oxidation of C1-C5 alkane quinternary natural gas mixtures at high pressures, Energy Fuels, 24 (2010) 15211528.

45. S.M. Sarathy, C. Westbrook, M. Mehl, W. Pitz, C. Togbe, P. Dagaut, H. Wang, M. Oehlschlaeger, U. Niemann, K. Seshadri, Comprehensive chemical kinetic modeling of the oxidation of 2-methylalkanes from C7 to C20, Combust. Flame, 158 (2011) 2338-2357.

46. S.Y. Mohamed, L. Cai, F. Khaled, C. Banyon, Z. Wang, M.J. Al Rashidi, H. Pitsch, H.J. Curran, A. Farooq, S.M. Sarathy, Modeling Ignition of a Heptane Isomer: Improved Thermodynamics, Reaction Pathways, Kinetics, and Rate Rule Optimizations for 2-Methylhexane J. Phys. Chem. A (2016). DOI: 10.1021/acs.jpca.6b00907.

47. D. Healy, N. Donato, C. Aul, E. Petersen, C. Zinner, G. Bourque, H.J. Curran, n-Butane: Ignition delay measurements at high pressure and detailed chemical kinetic simulations, Combust. Flame, 157 (2010) 1526-1539.

48. Y. Zhang, K.P. Somers, M. Mehl, W.J. Pitz, R.F. Cracknell, H.J. Curran, Probing the Antagonistic Effect of Toluene as a Component in Surrogate Fuels Models at Low Temperatures and High Pressures. A Case Study of Toluene/Dimethyl Ether Mixtures, Proc. Combust. Inst. (2016) Accepted.

49. D. Darcy, H. Nakamura, C. Tobin, M. Mehl, W.K. Metcalfe, W.J. Pitz, C.K. Westbrook, H.J. Curran, A high-pressure rapid compression machine study of n-propylbenzene ignition, Combust. Flame, 161 (2014) 65-74.

50. D. Darcy, H. Nakamura, C.J. Tobin, M. Mehl, W.K. Metcalfe, W.J. Pitz, C.K. Westbrook, H.J. Curran, An experimental and modeling study of surrogate mixtures of n-propyl- and nbutylbenzene in n-heptane to simulate n-decylbenzene ignition, Combust. Flame, 161 (2014) 1460-1473. 
51. D. Darcy, M. Mehl, J.M. Simmie, J. Würmel, W.K. Metcalfe, C.K. Westbrook, W.J. Pitz, H.J. Curran, An experimental and modeling study of the shock tube ignition of a mixture of n-heptane and n-propylbenzene as a surrogate for a large alkyl benzene, Proc. Combust. Inst. 34 (2013) 411-418.

52. H. Nakamura, D. Darcy, M. Mehl, C.J. Tobin, W.K. Metcalfe, W.J. Pitz, C.K. Westbrook, H.J. Curran, An experimental and modeling study of shock tube and rapid compression machine ignition of n-butylbenzene/air mixtures, Combust. Flame, 161 (2014) 49-64.

53. Y. Pei, M. Mehl, W. Liu, T. Lu, W.J. Pitz, S. Som, A Multi-Component Blend as a Diesel Fuel Surrogate for Compression Ignition Engine Applications, J. Eng. Gas Turb. Power, 137 GTP-15-1057 (2015) 1-15.

54. W.K. Metcalfe, S. Dooley, F.L. Dryer, Comprehensive detailed chemical kinetic modeling study of toluene oxidation, Energy Fuels, 25 (2011) 4915-4936.

55. M.B. Sajid, M. Al Rashidi, M. Mehl, W.J. Pitz, S.M. Sarathy, A. Farooq, Shock tube ignition measurements and modeling of cyclopentane, 9th U.S. National Combustion Meeting (2015).

56. M.J. Al Rashidi, S. Thion, C. Togbé, G. Dayma, M. Mehl, P. Dagaut, W.J. Pitz, J. Zádor, S.M. Sarathy, Elucidating reactivity regimes in cyclopentane oxidation: jet stirred reactor experiments, computational chemistry, and kinetic modeling, Proc. Combust. Inst. (2016) Accepted.

57. S.M. Burke, W. Metcalfe, O. Herbinet, F. Battin-Leclerc, F.M. Haas, J. Santner, F.L. Dryer, H.J. Curran, An experimental and modeling study of propene oxidation. Part 1: Speciation measurements in jet-stirred and flow reactors, Combustion and Flame 161 (2014) 2765-2784.

58. C.-W. Zhou, Y. Li, E. O'Connor, K.P. Somers, S.B. Thion, C. Keesee, O. Mathieu, E.L. Petersen, T.A. DeVerter, M.A. Oehlschlaeger, G. Kukkadapu, C.-J. Sung, M. Alrefae, F. Khaled, A. Farooq, P. Dirrenberger, P.-A. Glaude, F.D.R. Battin-Leclerc, J. Santner, Y. Ju, T. Held, F.M. Haas, F.L. Dryer, H.J. Curran, A comprehensive experimental and modeling study of isobutene oxidation Combustion and Flame (2016) http://dx.doi.org/10.1016/j.combustflame.2016.01.021

59. J. Bugler, K.P. Somers, E.J. Silke, H.J. Curran, Revisiting the Kinetics and Thermodynamics of the Low- Temperature Oxidation Pathways of Alkanes: A Case Study of the Three Pentane Isomers, J. Phys. Chem. A 119 (2015) 7510-7527. 
60. J. Bugler, B. Marks, O. Mathieu, R. Archuleta, A. Camou, C. Grégoire, K.A. Heufer, E.L. Petersen, H.J. Curran, An ignition delay time and chemical kinetic modeling study of the pentane isomers, Combustion and Flame 163 (2016) 138-156.

61. K. Zhang, C. Banyon, C. Togb, P. Dagaut, J. Bugler, H.J. Curran, An experimental and kinetic modeling study of n-hexane oxidation, Combustion and Flame 162 (2015) 41944207.

62. Z. Wang, S.M. Sarathy, Third O2 addition reactions promote the low-temperature autoignition of n-alkanes, Combustion and Flame 165 (2016) 364-372.

63. Z. Wang, L. Zhang, K. Moshammer, L. Zhang, K. Moshammer, D.M. Popolan-Vaida, V.S.B. Shankar, A. Lucassen, C. Hemken, C.A. Taatjes, S.R. Leone, K. Kohse-Höinghaus, N. Hansen, P. Dagaut, S.M. Sarathy, Additional chain-branching pathways in the lowtemperature oxidation of branched alkanes, Combustion and Flame 164 (2016) 386-396

64. David G. Goodwin, Harry K. Moffat, and Raymond L. Speth. Cantera: An object- oriented software toolkit for chemical kinetics, thermodynamics, and transport processes. http://www.cantera.org, 2015. Version 2.2.0.

65. G.L. Goteng, M. Speight, N. Nettyam, A. Farooq, M. Frenklach, S.M. Sarathy, A hybrid cloud system for combustion kinetics simulation, 23rd International Symposium on Gas Kinetics and Related Phenomena, 23rd International Symposium on Gas Kinetics and Related Phenomena, Hungary, 2014.

66. Z. Reyno-Chiasson, N. Nettyam, G. L. Goteng, M. Speight, B. J. Lee, S. Baskaran, J. Oreluk, A. Farooq, H. G. Im, M. Frenklach, S. M. Sarathy, CloudFlame and PrIMe: accelerating combustion research in the cloud, 9th International Conference on Chemical Kinetics, Belgium, (2015).

67. CHEMKIN-PRO 15112, Reaction Design, San Diego, 2011.

68. J. L. Burger, N. Schneider, T. J. Bruno, Application of the advanced distillation curve method to fuels for advanced combustion engine gasolines, Energy Fuels 29 (7)(2015) 4227-4235.

69. T. J. Bruno, L. S. Ott, B. L. Smith, T. M. Lovestead, Complex Fluid Analysis with the Advanced Distillation Curve Approach, Anal. chem. 82 (3)(2010) 777-783

70. G.T. Kalghatgi, L. Hildingsson, A.J. Harrison, B. Johansson, Surrogate fuels for premixed combustion in compression ignition engines, International Journal of Engine Research 12 (2011) 452-465. 
71. V. Knop, M. Loos, C. Pera, N. Jeuland, A linear-by-mole blending rule for octane numbers of n-heptane/iso-octane/toluene mixtures, Fuel 115 (2014) 666-673.

72. F.M. Haas, F.L. Dryer, Application of blending rules for ignition quality metrics: A comment on "A linear-by- mole blending rule for octane numbers of n-heptane/isooctane/toluene mixtures", Fuel 120 (2014) 240-242.

73. P. Ghosh, K.J. Hickey, S.B. Jaffe, Ind. Eng. Chem. Res. 45 (2006) 337-345.

74. Lemmon EW, Huber ML, McLinden MO. NIST reference fluid thermodynamic and transport properties-REFPROP. Version 9.0 (2010).

75. C.J. Mueller, W.J. Cannella, T.J. Bruno, B. Bunting, H.D. Dettman, J.A. Franz, M.L. Huber, M. Natarajan, W.J. Pitz, M.A. Ratcliff, Methodology for formulating diesel surrogate fuels with accurate compositional, ignition-quality, and volatility characteristics, Energy Fuels 26 (6) (2012) 3284-3303.

76. S. Japanwala, K. H. Chung, H. D. Dettman, M. R. Gray, Quality of distillates from repeated recycle of residue, Energy Fuels 16 (2) (2002) 477-484.

77. M. Huber, B. Smith, L. Ott, T. Bruno, Surrogate mixture model for the thermophysical properties of synthetic aviation fuel S-8: explicit application of the advanced distillation curve, Energy Fuels 22 (2) (2008) 1104-1114.

78. W. R. Leppard, The chemical origin of fuel octane sensitivity, SAE Technical Paper: 902137 (1990) 1-13.

79. S.S. Goldsborough, M.V. Johnson, C. Banyon, W.J. Pitz, M.J. McNenly, Experimental and modeling study of fuel interactions with an alkyl nitrate cetane enhancer, 2-ethyl-hexyl nitrate, Proc. Combust. Inst. 35 (1) (2015) 571-579.

80. Y. Yang, J. E. Dec, N. Dronniou, M. Sjöberg, Tailoring HCCI heat-release rates with partial fuel stratification: Comparison of two-stage and single-stage-ignition fuels, Proc. Combust. Inst. 33 (2) (2011) 3047-3055.

81. S.S. Merchant, C.F. Goldsmith, A.G. Vandeputte, M.P. Burke, S.J. Klippenstein, W.H. Green, Understanding low-temperature first-stage ignition delay: Propane, Combust. Flame 162 (2015) 3658-3673.

82. C. K. Westbrook, Chemical kinetics of hydrocarbon ignition in practical combustion systems, Proc. Combust. Inst. 28 (2000) 1563-1577. 
83. S.H. Won, S. Dooley, P.S. Veloo, H. Wang, M.A. Oehlschlaeger, F.L. Dryer, Y. Ju, Quantification of Molecule Structure Impact on Combustion Properties for Synthetic Diesel Fuel: 2, 6, 10-Trimethyldodecane, 8th U.S. National Combustion Meeting (2013) 1-9.

84. M.N. Lapuerta, J.J. Hernández, S.M. Sarathy, Effects of methyl substitution on the autoignition of C16 alkanes, Combustion and Flame 164 (2016) 259-269.

85. D.J.M. Ray, D. J. Waddington, Gas phase oxidation of alkenes-Part II. The oxidation of 2methylbutene-2 and 2,3-dimethylbutene-2, Combust. Flame 20 (1973) 327-334.

86. M.I. Sway, D.J. Waddington, Reactions of oxygenated radicals in the gas phase. Part 12. The reactions of isopropylperoxyl radicals and alkenes, J. Chem. Soc., Perkin Trans. 2 (1983) 139-143.

87. A. Roubaud, O. Lemaire, R. Minetti, L.R. Sochet, High pressure auto-ignition and oxidation mechanisms of o-xylene, o-ethyltoluene, and n-butylbenzene between 600 and $900 \mathrm{~K}$, Combust. Flame 123 (2000) 561-571.

88. A. Roubaud, R. Minetti, L.R. Sochet, Oxidation and combustion of low alkylbenzenes at high pressure: comparative reactivity and auto-ignition, Combust. Flame 121 (2000) 535541.

89. G. Vanhove, G. Petit, R. Minetti, Experimental study of the kinetic interactions in the lowtemperature autoignition of hydrocarbon binary mixtures and a surrogate fuel, Combust. Flame 145 (2006) 521-532.

90. J. Zádor, C.A. Taatjes, R.X. Fernandes, Prog. Kinetics of elementary reactions in lowtemperature autoignition chemistry, Prog. Energy Combust. Sci. 37 (2011) 371-421.

91. G. da Silva, J.W. Bozzelli, Benzoxyl Radical decomposition kinetics: formation of benzaldehyde $+\mathrm{H}$, phenyl $+\mathrm{CH} 2 \mathrm{O}$, and benzene $+\mathrm{HCO}$, J. Phys. Chem. A 113 (2009) 6979-6986.

92. S. Dooley, J. Heyne, S.H. Won, P. Diévart, Y. Ju, F.L. Dryer, Importance of a cycloalkane functionality in the oxidation of a real fuel, Energy Fuels 28 (2014) 7649-7661.

93. Y. Yang, J. E. Dec, N. Dronniou, M. Sjöberg, W. Cannella, Partial Fuel Stratification to Control HCCI Heat Release Rates: Fuel Composition and Other Factors Affecting PreIgnition Reactions of Two-Stage Ignition Fuels, SAE Int. J. Engines 4(1) 2011-01-1359.

94. M. Yao, H. Liu, B. Zhang, Z. Zheng, The Influence of Boost Pressure and Fuel Chemistry on Combustion and Performance of a HCCI Engine, SAE Technical Paper: 2008-01-0051. 
95. D. Vuilleumier, H. Selim, R. Dibble, M. Sarathy, Exploration of Heat Release in a Homogeneous Charge Compression Ignition Engine with Primary Reference Fuels, SAE Technical Paper: 2013-01-2622.

96. D. Vuilleumier, D. Kozarac, M. Mehl, S. Saxena, W. J. Pitz, R. W. Dibble, J.-Y. Chen, S. M. Sarathy, Intermediate temperature heat release in an HCCI engine fueled by ethanol/nheptane mixtures: An experimental and modeling study, Combust. Flame 161 (3) (2014) 680-695.

97. J. E. Dec, Advanced compression-ignition engines-understanding the in-cylinder processes, Proc. Combust. Inst. 32 (2) (2009) 2727-2742.

98. M. P. Musculus, P. C. Miles, L. M. Pickett, Conceptual models for partially premixed lowtemperature diesel combustion, Prog. Energy Combust. Sci. 39 (2) (2013) 246-283.

99. S. Saxena, I. D. Bedoya, Fundamental phenomena affecting low temperature combustion and HCCI engines, high load limits and strategies for extending these limits, Prog. Energy Combust. Sci. 39 (5) (2013) 457-488. 